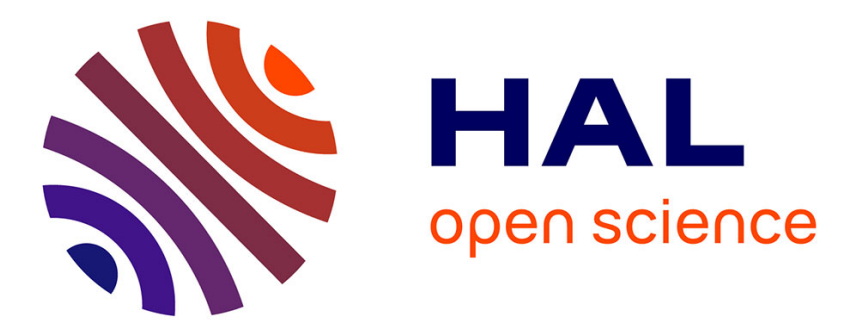

\title{
Comparison of mechanical properties of C-S-H and portlandite between nano-indentation experiments and a modeling approach using various simulation techniques
}

\author{
J. Fu, Siham Kamali-Bernard, Fabrice Bernard, M. Cornen
}

\section{- To cite this version:}

J. Fu, Siham Kamali-Bernard, Fabrice Bernard, M. Cornen. Comparison of mechanical properties of C-S-H and portlandite between nano-indentation experiments and a modeling approach using various simulation techniques. Composites Part B: Engineering, 2018, 151, pp.127-138. 10.1016/j.compositesb.2018.05.043 . hal-01835012

HAL Id: hal-01835012

https://hal-univ-rennes1.archives-ouvertes.fr/hal-01835012

Submitted on 13 Jul 2018

HAL is a multi-disciplinary open access archive for the deposit and dissemination of scientific research documents, whether they are published or not. The documents may come from teaching and research institutions in France or abroad, or from public or private research centers.
L'archive ouverte pluridisciplinaire HAL, est destinée au dépôt et à la diffusion de documents scientifiques de niveau recherche, publiés ou non, émanant des établissements d'enseignement et de recherche français ou étrangers, des laboratoires publics ou privés. 
Comparison of mechanical properties of C-S-H and Portlandite between nano-indentation experiments and a modelling approach using various simulation techniques

$\mathrm{Jia} \mathrm{Fu}^{\mathrm{a}, \mathrm{b}}$, Siham Kamali-Bernard ${ }^{\mathrm{a}}$, Fabrice Bernard ${ }^{\mathrm{a}^{*}}$, Marilyne Cornen ${ }^{\mathrm{c}}$

${ }^{\text {a }}$ Laboratory of Civil Engineering and Mechanical Engineering, National Institute of Applied Sciences, INSA-Rennes, 35708 Rennes Cedex 7, FRANCE;

${ }^{\mathrm{b}}$ Xi'an Shiyou University, Xi'an, Shaanxi Province,710065, P. R. CHINA

${ }^{\mathrm{c}}$ UMR CNRS 6226 Institut Sciences Chimique de Rennes/Chimie-métallurgie, INSA Rennes, 35708 Rennes Cedex 7, FRANCE

* Corresponding author: Fabrice.Bernard@insa-rennes.fr 


\section{Abstract}

This work focuses on elastic modulus of two main constituents of cement based materials: portlandite $(\mathrm{CH})$ and Calcium Silicates Hydrates $(\mathrm{C}-\mathrm{S}-\mathrm{H})$. At nano-scale, the single $\mathrm{CH}$ crystal using Density Functional Theory (DFT) is investigated and the homogenised elastic modulus is obtained to be assessed as the RVE unit, which is used in nano-indentation simulation. Then the monolithic C-S-H structure with the chemical formula: $(\mathrm{CaO})_{1.67}\left(\mathrm{SiO}_{2}\right)\left(\mathrm{H}_{2} \mathrm{O}\right)_{1.75}$ is simulated during the stretch process at strain rate $10^{-3} \mathrm{ps}^{-1}$ by Molecular Dynamics (MD) method using ClayFF field, and its averaged elastic modulus is used to assess Young's moduli of LD and HD C-S-H phases considering the porosity factor. Then at micro scale, FEM is used to simulate the nano-indentation test on ABAQUS software and Young moduli of $\mathrm{CH}$ and $\mathrm{C}-\mathrm{S}-\mathrm{H}$ phases are determined by the load-depth curve. Young modulus by the load-depth curve simulated is calculated to compare with the experimental one. The results show that: 1) the Young's modulus calculated by DFT and Reuss-Voigt-Hill (RVH) calculation is $45.46 \mathrm{GPa}$, which is in quite good agreement with experimental averaged value $(39.88 \mathrm{GPa})$ and with the literatures values (45.94 GPa by Laugesen, 52.4 GPa by Speziale et al., 44.69 GPa by Kerisit et al., $46.58 \mathrm{GPa}$ by Holuj et al.). 2) Based on the elastic modulus of the monolithic C-S-H structure by MD simulations, the assessment results on LD C-S-H and HD C-S-H after homogenization are very close to nanoindentation experiments data. 3) By FEM method, the simulated P-h curve is adopted to compare the extent of deviation from the experimental values, which is within an acceptable relative error. The homogenized elastic properties of polycrystals can be obtained by elastic constants of single crystal (using DFT and $\mathrm{RVH}$ estimation), thus can be used to explain the relationship between structure and mechanical properties of $\mathrm{CH}$ from nano-scale to micro-scale. Results enable to provide useful parameters for composite cements systems modeling and a method to calculate elastic modulus of other similar structures.

\section{Keywords}

Portlandite; Calcium Silicates Hydrates; Elastic modulus; Nano-indentation; DFT; MD; FEM 


\section{Introduction}

Modeling the structural concrete performances needs a precise assessment of the mechanical properties of cementitious composites [1], and the different scales have to be considered to reflect the atomic interactions [2] at different length-scales [3]. Nano-indentation technique as well as Density Functional Theory (DFT) can be combined to study mechanical properties of the two main phases of Hardened Cement Pastes, namely Hydrated Calcium Silicates $(\mathrm{C}-\mathrm{S}-\mathrm{H})$ and Portlandite $(\mathrm{CH}) . \mathrm{CH}$ and $\mathrm{C}-\mathrm{S}-\mathrm{H}$ as the main and typical constituents of hydrated cementitious systems separately represents approximately $70 \%$ and $17-25 \%$ of the volume fraction of portland cement paste [4]. Both of them influence the physical and mechanical properties as well as the durability of composite cementitious materials. Their Young's moduli are needed in the modeling of cement at the macro and micro scales [5]. The traditional continuum models [6] and nonlocal continuum theory [7] are not adequate in modeling [8] of these materials [9]. Nano-indentation experiment as an advanced micro-scale mechanical measurement techniques is widely used in the characterization of mechanical behavior at small scales $[10,11]$, thus providing the elastic modulus of cement hydration products $[12,13]$.

Nano-indentation experiment has been widely adopted to investigate the local mechanical properties of materials and to characterize mineral and metal materials [14] used in the fields of medical devices, micro-electro mechanical systems (MEMS), bio-engineering, civil engineering, aircraft and film material research[15]. This technique is being used increasingly to measure hardness, elastic modulus, creep parameters and residual stresses thanks to high resolution load control and displacement sensing capabilities. This tool is particularly useful to characterize microscale heterogeneities in materials or local mechanical properties at the grain scale in polycrystalline or multiphase samples. However, Nano-indentation has a complex problem of contact, which is affected by many factors, such as the surface roughness, the substrate effect, the grain boundary effects, indenter geometry, lattice anisotropy and size effect, etc. Even though the nano-indentation process is performed in the same device and under the same test conditions, the results can not be guaranteed repeatable. That is why the investigation of nano-indentation process using numerical simulation method is required. As its theoretical mechanism is very complex [16] and size effect $[17,18]$ are not commonly considered, both experiment and simulation are used for comparison of mechanical properties of $\mathrm{CH}$ and $\mathrm{C}-\mathrm{S}-\mathrm{H}$ according to loading/unloading curves between load and displacement. Although there are some relative reports on nano-indentation 
technique, these studies are almost based on experimental analysis and the numerical calculation of $\mathrm{CH}$ and $\mathrm{C}-\mathrm{S}-\mathrm{H}$ structure at nano-scale has not yet been revealed.

The crystal structure of $\mathrm{C}-\mathrm{S}-\mathrm{H}$ structure is basically known and commonly modeled as tobermorite-like (i.e., tobermorite $9 \AA, 11 \AA$, 14 $)$ and jennite-like systems [19] and/or with distorted semi-crystalline variations of them [20]. Tobermorite as one of the earliest models proposed by Taylor and Howison [21] is thought as its hydration degree, which may describe the relative C-S-H nanostructure. From the view of $\mathrm{Ca} / \mathrm{Si}$ ratio, there are two types $\mathrm{C}-\mathrm{S}-\mathrm{H}$ structures: the $\mathrm{C}-\mathrm{S}-\mathrm{H}(\mathrm{I})$ (with $\mathrm{Ca} / \mathrm{Si}$ of 0.6 1.5) and $\mathrm{C}-\mathrm{S}-\mathrm{H}(\mathrm{II})$ structures [22] (with $\mathrm{Ca} / \mathrm{Si}$ of 1.5 2.0), of which the later is close to the experimentally confirmed structure $\mathrm{C}_{1.7}-\mathrm{S}-\mathrm{H}_{1.8}$ with $\mathrm{Ca} / \mathrm{Si}$ of 1.7 in the $\mathrm{C}-\mathrm{S}-\mathrm{H}$ gel [23]. From the view of several nanometers length scale, C-S-H gel has a nano-granular aspect composed of monolithic C-S-H (full dense C-S-H) and porosity. At this scale, C-S-H gel "Globule" model exists in two forms: Low Density C-S-H (LD C-S-H) and High Density C-S-H (HD C-S-H), provided by Jennings [24]. Hou Dong Shuai et al. [25] have investigated an amorphous C-S-H structure on the elastic properties of the layered C-S-H based on the CSH-FF field. Moreover, Microporomechanics technique has been used to calculate elastic properties of LD C-S-H and HD C-S-H gels [26]. For the elastic properties of LD and HD C-S-H, Constantinides et al. [27] have obtained elastic moduli by nanoindentation experiment. The porosity is also a factor influencing the elastic modulus of cement paste [28]. It has been investigated based on the backscattered electron image analysis and the HYMOSTRUC model [29]. The impact of the porosity on the matrix Young modulus is that the Young modulus decreases highly with the increasing of the porosity [30]. According to LD and HD C-S-H models described by Jennings [25], the gel porosity of LD C-S-H solid phase is $35-37 \%$, while the gel porosity of HD C-S-H solid phase is $24 \%$. However, the relationship between the C-S-H structure with the size of about $5 \mathrm{~nm}$ and C-S-H phases (LD C-S-H and HD C-S-H) has not been revealed yet. In this paper the porosity and homogenization are used to explain the difference, which is meaningful for the verification of both the nano-indentation simulation and nano-indentation experiment.

The crystal structure of $\mathrm{CH}$ is well known, where the morphology of the crystal is hexagonal with space group $\mathrm{P} 3 \mathrm{~m} 1$. This work focuses also on the modelling and mechanical properties of $\mathrm{CH}$ structure from nano-scale to micro-scale. Modelling and simulation of continuum coupling in computational hydrates structures with the size of nanometer unit during nonlinear 
micro-indentation is considered and simulated to compare experimental results performed in this work and by Keinde [30] and Constantinides [32], of which the obtained elastic moduli were close to Brillouin spectroscopy measurements [33], and other modelling and experimental results [34]. The load-depth curve and elastic properties of the two phases are also investigated. Results enable to provide useful parameters for hydrated lime, Portland and composite cement systems modeling and a method to calculate elastic modulus of other similar structures.

\section{Modeling of the structure of hydrates at nano-scale and nano-indentation investigation at micro-scale}

\subsection{Modeling and computational detail of $\mathrm{CH}$ crystal}

Cambridge sequential total energy package (CASTEP) [35,36] and first-principles plane wave pseudopotential method based on DFT is adopted. The exchange correlation potential includes the generalized gradient approximation (GGA) and the local density approximation (LDA), which are in the scheme of Perdew-Burke-Eruzerh of (PBE) [37] and Ceperley-Adler parameterized by Perdew and Zunger [38,39]. The nucleus-nucleus and electron-electron interactions are also considered [40]. Initial model and flowchart are in Fig.1.

[FIGURE 1]

Fig.1a) shows that $\mathrm{Ca}^{2+}$ is mainly octahedrally coordinated by the oxygen atoms. The hydrogen bond or other strong bonds across the layer is not existed. DFT calculation process is shown in Fig. $1 \mathrm{~b}$ ), the pressure region is $0 \sim 1.0 \mathrm{GPa}$. Initial conditions are as: the exchange-correlation function is GGA; The cutoff energy of the plane waves for ultrasoft pseudopotentials is $500 \mathrm{eV}$. Brillouin zone is $15 \times 15 \times 15$. The self-consistent convergence of the total energy is $10^{-6} \mathrm{eV}$ per atom.

\subsection{Modeling and computational detail of monolithic C-S-H}

The construction of an amorphous monolithic C-S-H(II) is largely developed in reference [41]. Only a brief description is given here. The construction of a monolithic "Globule" C-S-H structure is shown in Fig.2. 
[FIGURE 2]

Steps for construction of the amorphous C-S-H structure of about $2 \mathrm{~nm}$ with $\mathrm{Ca} / \mathrm{Si}$ ratio of 1.67 in Fig.2 (a) for modelling and simulation are as: Step 1: The construction of dry amorphous C-S-H structure with formula: $(\mathrm{CaO})_{1.67}\left(\mathrm{SiO}_{2}\right)$, where the dry C-S-H model: $\mathrm{Q}_{0}, \mathrm{Q}_{1}$ and $\mathrm{Q}_{2}$ are separately 13\%, 67\% and 20\%. Step 2: Water adsorption of dry C-S-H by Grand Canonical Monte Carlo (GCMC) simulation, and the final C-S-H formula is $(\mathrm{CaO})_{1.67}\left(\mathrm{SiO}_{2}\right)\left(\mathrm{H}_{2} \mathrm{O}\right)_{1.75}$, with the density of $2.257 \mathrm{~g} / \mathrm{cm}^{3}$. Finally, the monolithic "Globule" C-S-H structure about $5 \mathrm{~nm}$ is periodically constructed based on the size of about $2.5 \mathrm{~nm}$, shown in Fig.2(b).

We use the ClayFF field [42] and Lammps package code [43] for our calculations. The Coulomb interaction by Eward truncation radius is $10.0 \AA$. The Lennard-Jones potential cutoff radius is $8.0 \AA$. In simulation, NPT ensembles are set for the system. A timestep of $0.01 \mathrm{fs}$ is used. The others setting parameters has been given in previous studies [42]. Then the model was subjected to uniaxial tensile loads through gradual elongation in three directions with a strain rate of $0.001 \mathrm{ps}^{-1}$.

\subsection{Continuum Model in nano-indentation simulation}

At the meso-scale, subdomains are regarded with locally varying loads. The interaction of the constituents is accounted for at the micro-scale [43]. The nano-indentation constitutive model with embedded programs was done to simulate nano-indentation process by FE analysis as shown in Fig.3.

\section{[FIGURE 3]}

From Fig.3 a) the 3D model has a size of $15.0 \mu \mathrm{m} \times 15.0 \mu \mathrm{m} \times 7.5 \mu \mathrm{m}$, which has the sufficient space to compare the experimental results. According to literatures [45,46], 3D models can be equivalent to an axisymmetric 2D model and the results of two models are consistent with each other. The size of the 2D model regarded as the semi-infinite solid in Fig.3 b) is $12.0 \mu \mathrm{m} \times$ $12.0 \mu \mathrm{m}$. This continuum space is discretized using the CPE4R element with higher accuracy. The Berkovich indenter is modeled as a conical indenter with a semi-apex angle of $70.32^{\circ}$, where the 
conical cross-sectional area closest to the actual situation. To simplify the calculation, Berkovich indenter is assumed to be rigid and the deformation is subjected to the Mises yield criterion and isotropic hardening criterion. For save the computational time, the transitional gird division method is adopted. The element size in the indenter contact region was continuously refined to a greater accuracy, a refined mesh in Fig.2 3) was near the tip area (contact zone is $3.0 \mu \mathrm{m} \times 3.0 \mu \mathrm{m}$, the number of grid is $300 \times 300$ ) in order to maintain the reasonable accuracy and the refined mesh in the indenter region. The minimum length of elements within the final domain is about $10 \mathrm{~nm}$.

\subsection{Description of nano-indentation experiment process}

Nano-indentation instrument of INSA de Rennes and sample are shown in Fig.4.

\section{[FIGURE 4]}

As it can be seen in Fig. 4 a), the device used for our experiments is an OpenPlatform from CSM instruments which includes several heads: on the left, the first piece of apparatus is a scratch tester, then follows the nano-indentation tester (NHT), a confocal pen (Conscan), an atomic force microscopy (AFM) system and finally besides is an optical microscope. For the experiments a modified Berkovich indenter is used, as shown in Fig.4 b). The Berkovich indenter is a three-sided pyramid diamond which is geometrically self-similar and the modified tip has an half angle of $65.27^{\circ}$ that allows it to have the same projected area as a Vickers tip whatever the indentation depth is. Samples with approximately $1.1 \mathrm{~cm} \times 1.1 \mathrm{~cm} \times 1.5 \mathrm{~cm}$ of dimensions (Fig.4 c)) are used. During their surface preparation they underwent rigorous mechanical polishing in order to reach a mirror surface. Parameters of the indentation tests are as follows: a standard process is chosen, that means an approach speed of $2000 \mathrm{~nm} / \mathrm{s}$, a linear loading and unloading in $30 \mathrm{~s}$, and the maximum load is fixed to $1.5 \mathrm{mN}$;. For each experiment, the data of load and displacement are recorded. The test is repeated several times in a chosen region of the same paste with a sufficient distance between 2 nanoindentations in order to avoid influence of prints on each other's.

\section{Theoretical analysis and elastic modulus calculation of P-h curve}

\subsection{The analysis of the force-depth curve}


The nano-indentation test is a technique in which the penetration depth is measured in nanometers continuously during the loading process. This allows to indirectly measure the contact area that is the real area where contact is made between the indenter and the tested material. Indeed, in conventional indentation test, the contact area is calculated by measuring the size of the residual print on the surface of the sample after unloading. But in the nano-indentation test, the contact surface is determined indirectly from the geometry of the indenter and the depth of penetration; meanwhile, the force and the displacement of the tip in the material are continuously recorded and shown in a force-depth curve, as shown in Fig.5.

\section{[FIGURE 5]}

As it is shown in Fig.5, $\mathrm{P}_{\max }$ is the maximum of loading stress, $\mathrm{h}_{\max }$ is the maximum of indentation depth, $h_{p}$ is the residual depth of the print $h_{r}$ is the sinking, obtained by drawing the tangent of the unloading curve at $\mathrm{P}_{\max }, \mathrm{S}$ is the initial unloading contact stiffness, $\mathrm{h}_{\mathrm{c}}$ is the contact depth which is calculated (explained in 3.2). The typical indentation curve in Fig.5 represents a loading-unloading cycle, not superimposed when the test leaves a permanent track on the surface. The first part is the loading curve corresponding to the penetration of the indenter. This ends when the indenter reaches its maximum load $\mathrm{P}_{\max }$ or the maximum penetration $\mathrm{h}_{\max }$. The second part represents the discharge curve. It corresponds to the withdrawal of the indenter. The analysis of a cycle gives a lot of information by reading the indentation curve total penetration depth $\mathrm{h}_{\max }$ and the residual depth $h_{p}$. Furthermore, studying the areas under the curves is interesting because information such as elastic work $\left(\mathrm{W}_{\mathrm{e}}\right)$ and plastic work $\left(\mathrm{W}_{\mathrm{p}}\right)$ can be assessed. For example, surface enclosed by the unloading curve, horizontal axis and the vertical ordinate of maximum load represents elastic deformation work.

\subsection{Theoretical calculation of elastic modulus by the P-h curve}

Generally speaking, the unloading stiffness $\mathrm{S}$ is established by differentiating $\mathrm{P}$ at the maximum depth of penetration. $\mathrm{S}$ is the initial unloading contact stiffness represented by the slope of the initial portion of the unloading curve, which is as:

$$
S=\left(\frac{d P}{d h}\right)_{h=h_{\max }}
$$


The contact area as a function of contact depth $h_{c}$ is calibrated by indenting on a standard cement specimen.

The contact depth $h_{c}$ can be obtained by the load-displacement curve using Sneddon's equation [47] and assuming that pile-up is negligible:

$$
h_{c}=h_{\max }-\varepsilon \frac{P_{\max }}{S}
$$

Where $\varepsilon$ is a constant depending on the indenter geometry; $\varepsilon=0.75$ for the Berkovich indenter, $\varepsilon=0.72$ for the conical indenter, and $\varepsilon=1$ for the flat punch.

The unloading part of the curve enables to characterize the elastic behaviour of the indented phase and more particularly its reduced modulus $\mathrm{E}_{\mathrm{r}}$.

The reduced modulus can be defined as:

$$
E_{r}=\frac{\sqrt{\pi}}{2 \beta} \frac{S}{\sqrt{A}}
$$

It is related to the Young's modulus and the Poisson's ratio of the phase by means of the following relationship:

$$
\frac{1}{E_{r}}=\frac{1-v^{2}}{E}+\frac{1-v_{i}^{2}}{E_{i}}
$$

In these two equations, $\beta$ is the indenter shape function, the area $\mathrm{A}$ depends on the penetration depth and is calibrated using the procedure of Oliver and Pharr [11], E and v are the elastic modulus and Poisson's ratio of the specimen, and $\mathrm{E}_{\mathrm{i}}$ and $v_{\mathrm{i}}$ are those of the indenter. For a diamond indenter, $\mathrm{E}_{\mathrm{i}}=1140 \mathrm{GPa}$ and $v_{\mathrm{i}}=0.07$.

According to Tabor [48], by the analyzing of elastic properties using nano-indentation data, the yield stress can be roughly assessed, which is directly correlated with hardness value as:

$$
\sigma_{y} \approx H / C
$$

Where $\mathrm{H}$ is indentation hardness (GPa), $\mathrm{C}$ is the contact creep modulus (GPa), the coefficient can change in the range of 2.6-3.0.

\section{Results analysis and discussion}

\subsection{Elastic modulus calculation of CH, LD C-S-H and HD C-S-H}

\subsubsection{Axial modulus and homogenized modulus of $\mathrm{CH}$}


The elastic constants for hexagonal are: $\mathrm{C}_{11}, \mathrm{C}_{12}, \mathrm{C}_{13}, \mathrm{C}_{33}$ and $\mathrm{C}_{44}$, since $\mathrm{C}_{66}=\left(\mathrm{C}_{11}-\mathrm{C}_{12}\right) / 2$, and the corresponding mechanical stability condition [49] are :

$$
\begin{aligned}
& C_{11}>0, C_{11}-C_{12}>0, \\
& C_{44}>0,\left(C_{11}+C_{12}\right) C_{33}-2 C_{13}^{2}>0 .
\end{aligned}
$$

Bulk modulus $\mathrm{B}$ and shear modulus $\mathrm{G}$ of $\mathrm{CH}$ can be calculated by Voigt-Reuss-Hill (VRH) estimation [50]. The Voigt bounds of B and $\mathrm{G}$ are:

$$
\begin{aligned}
& B_{V}=\frac{2}{9}\left(C_{11}+C_{12}+\frac{1}{2} C_{33}+2 C_{13}\right) \\
& G_{V}=\frac{1}{30}\left(7 C_{11}-5 C_{12}+12 C_{44}+2 C_{33}-4 C_{13}\right)
\end{aligned}
$$

And the Reuss bounds are:

$$
\begin{aligned}
B_{R} & =\frac{\left(C_{11}+C_{12}\right)-2 C_{13}^{2}}{C_{11}+C_{12}+2 C_{33}-4 C_{13}} \\
G_{R} & =\frac{5}{2}\left\{\frac{\left[\left(C_{11}+C_{12}\right) C_{33}-2 C_{13}^{2}\right] C_{44} C_{66}}{3 B_{V} C_{44} C_{66}+\left[\left(C_{11}+C_{12}\right) C_{33}-2 C_{13}^{2}\right]\left(C_{44}+C_{66}\right)}\right\}
\end{aligned}
$$

As from the Voigt-Reuss-Hill(RVH) estimation [51]: $\mathrm{M}_{\mathrm{H}}=(1 / 2)\left(\mathrm{M}_{\mathrm{R}}+\mathrm{M}_{\mathrm{V}}\right), \mathrm{M}=\mathrm{B}, \mathrm{G}$. Young's modulus E and Poisson's ratio $\mu$ can be calculated by:

$$
\begin{aligned}
& E=\frac{9 B G}{3 B+G}=\frac{9\left(B_{V} / 2+B_{R} / 2\right)\left(G_{V} / 2+G_{R} / 2\right)}{3\left(B_{V} / 2+B_{R} / 2\right)+\left(G_{V} / 2+G_{R} / 2\right)} \\
& \mu=\frac{3 B-2 G}{2(3 B+G)}=\frac{3\left(B_{V} / 2+B_{R} / 2\right)-2\left(G_{V} / 2+G_{R} / 2\right)}{6\left(B_{V} / 2+B_{R} / 2\right)+2\left(G_{V} / 2+G_{R} / 2\right)}
\end{aligned}
$$

Young's modulus and Poisson's ratio can be calculated by Voigt and Reuss bounds as well as the averaging term [51].

Defining $\sigma_{11}=\mathrm{E}_{1} \varepsilon_{11}, \sigma_{22}=\mathrm{E}_{2} \varepsilon_{22}$ and $\sigma_{22}=\mathrm{E}_{2} \varepsilon_{22}$, the formula of axial modulus in $\mathrm{x}, \mathrm{y}, \mathrm{z}$-direction $\mathrm{E}_{3}$ is shown as [52]:

$$
\begin{aligned}
& E_{1}=E_{2}=\left(c_{11}-c_{12}\right)\left[1+\left(c_{12} c_{33}-c_{13}^{2}\right) /\left(c_{11} c_{33}-c_{13}^{2}\right)\right] \\
& E_{3}=c_{33}-2 c_{13}^{2} /\left(c_{11}+c_{12}\right)
\end{aligned}
$$

Elastic constants $C_{i j}$ based on DFT are calculated. By Eq.8-Eq.9, $\sigma_{x}=\sigma_{y}=86.4918 \varepsilon_{x}$, $\sigma_{\mathrm{z}}=31.7002 \varepsilon_{\mathrm{z}}$. For structure of polycrystals, the homogenized elastic modulus including shear modulus and bulk modulus can be calculated [52]. Firstly, based on the $\mathrm{C}_{\mathrm{ij}}$ calculated, shear modulus, bulk modulus and Young's modulus are determined by means of Voigt and Reuss bounds and 
shear/bulk modulus formulas by Wu et al. [52].

\section{[TABLE 1]}

Seen from Table 1, all the data are in good agreement. DFT results are slightly upper than values of Brillouin spectroscopy measurement. Elastic moduli by RVH estimation [52] are as: $\mathrm{B}=28.25 \mathrm{GPa}, \mathrm{G}=17.31 \mathrm{GPa}, \mathrm{E}=43.13 \mathrm{GPa}$ by RVH estimation. More particularly the results of our DFT methodology are compared to previous results using methods of Speziale [33] and of Laugesen [54]. The homogenized elastic modulus by cubic linear elements is used for nano-indentation simulation.

\subsubsection{The elastic moduli of the monolithic C-S-H, LD and HD C-S-H}

Using Molecular Dynamics simulation, we have investigated the structural and mechanical properties of the "Globule" C-S-H structure. Elastic modulus is obtained by calculating the slope of strain-stress curves on average. Then elastic modulus of the "Globule" C-S-H with a size of 5nm is used to the assessment of the elastic modulus of C-S-H phases (LD and HD C-S-H), where the porosity value is the critical factor for explaining the relationship between "Globule" C-S-H at nano-scale between C-S-H phases at microscale. Effect of the model size and the loading direction on strain-stress curves is shown in Fig.6.

\section{[FIGURE 6]}

From Fig.6, the presence of scale effect is observed; this means that, with the increase of size, the peak stress becomes lower. Besides, the averaged modulus of "Globule" C-S-H (5nm) in three directions is averaged to be $60.95 \mathrm{GPa}$ under $10^{-3} \mathrm{ps}^{-1}$ strain rate at $300 \mathrm{~K}$.

The monolithic C-S-H structure about $5 \mathrm{~nm}$ enables to evaluate elastic modulus of LD C-S-H and HD C-S-H using Self-Consistent and Mori-Tanaka schemes, shown in Fig.7. 
From Fig.7, LD C-S-H and HD C-S-H are 18.11 GPa and 31.45 GPa, using the Self-Consistent Scheme, which is close to the value of nano-indentation experiment by Constantinides [27]. Based on results of MD simulations, the assessment results of LD C-S-H and HD C-S-H after homogenization are very close to data of nanoindentation experiments.

\subsection{Microstructure and chemical composition}

To highlight the C-S-H and $\mathrm{CH}$ phases in the studied samples, JEOL 7100 TTLS scanning electron microscope equipped with EDS system for elemental analysis was used. The backscattered electron images of the regions of interest were obtained at a beam voltage of $10 \mathrm{kV}$ and working distance of $8.3 \mathrm{~mm}$. CH phase and C-S-H and their elastic moduli are then identified.

Figure 8 shows the indentation points mapped onto one backscattered electron image. A secondary electron image of one region of the indented area is also given showing the traces and the permanent deformation left by the indent. Figure 9 presents backscattered electron images of different area of the specimen. The EDS (energy dispersive X-ray spectrometry) analysis of different points of these zones allow the identification of portlandite $(\mathrm{CH})$ and $\mathrm{C}-\mathrm{S}-\mathrm{H}$ (II) with $\mathrm{Ca} / \mathrm{Si}$ of about 2.

[FIGURE 8]

[FIGURE 9]

\subsection{Elastic modulus analysis of CH, LD C-S-H and HD C-S-H phases in experiment}

\subsubsection{Elastic modulus analysis of $\mathrm{CH}$ phase in experiment}

According to the microstructure observed and confirmed, the indents of $\mathrm{CH}$ phase under different samples have been found and the corresponding P-h curves are pointed out. The representative experimental curves of $\mathrm{CH}$ phase characterized by individual elastic modulus are averaged, in Fig. 10.

[FIGURE 10]

From Fig.10 a), for $\mathrm{CH}$ phase in nano-indentation experiment, the averaged Young's modulus 
is equal to $44.7 \pm 4.5 \mathrm{GPa}$, which is close to the values of $40.3 \pm 4 \mathrm{GPa}$ by Constantinides [55] and $36 \pm 3$ GPa by Acker [56]. Fig.10 b) shows a representative experimental curve of the P-h curve, the load is about $1.5 \mathrm{mN}$ and the maximum indent depth is about $212.98 \mathrm{~nm}$. It is impossible to decorrelate $\mathrm{E}$ and $v$ without making an assumption on one of them. For example, the experimental elastic modulus of $\mathrm{CH}$ is $39.88 \mathrm{GPa}$ if $v$ is taken equal to 0.2 .

\subsubsection{Elastic modulus analysis of C-S-H phase in experiment}

According to the microstructure observed and confirmed, the indents of LD C-S-H phase under different samples were found and the corresponding P-h curves are pointed out. Representive experimental curves of outer LD C-S-H phase is shown in Fig.11.

\section{[FIGURE 11]}

From Fig.11 a), for LD C-S-H phase, the averaged Young's modulus is equal to 22.3 $\pm 2.7 \mathrm{GPa}$, which is close to the values of 18.2 $\pm 4.2 \mathrm{GPa}$ by Constantinides [57] and $20 \pm 2 \mathrm{GPa}$ by Acker [58]. Fig. 11 b) shows the representative experimental curve of LD C-S-H phase, with its corresponding elastic modulus of $17.35 \mathrm{GPa}$.

Similarly, according to the microstructure observed and confirmed, the indents of HD C-S-H phase under different samples were found and the corresponding P-h curves are pointed out. Representive experimental curves of HD C-S-H phases are shown in Fig.12.

\section{[FIGURE 12]}

From Fig.12 a), for HD C-S-H phase, the averaged Young's modulus is equal to 33.5 $\pm 3.6 \mathrm{GPa}$

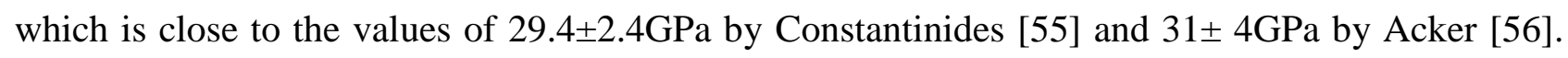
Fig. 12 b) shows the representative experimental curve of HD C-S-H phase, with its corresponding elastic modulus of $32.70 \mathrm{GPa}$.

Overall, nano-indentation experiments have given the range of elastic moduli: 15-26 GPa for LD C-S-H and 26-39 GPa for HD C-S-H. The inverse method described above is applied to each 
matrix phase. Finally, elastic moduli are calculated. The relative experimental parameters are listed in Table 2.

[TABLE 2]

Nano-indentation can be used to examine the mechanical properties of constituent phases independently especially for analysis of chemically complex phases, which will be discussed in the following section. As explained before, it is impossible to decorrelate $\mathrm{E}$ and $v$ without making an assumption on one of them. For example, the experimental elastic modulus of LD C-S-H is 17.35 GPa and HD C-S-H is $32.70 \mathrm{GPa}$ if $v$ is taken equal to 0.2 .

\subsection{Nano-indentation simulation by FEM}

Finite element analysis has been proved to be an effective method to obtain elastic modulus using the RVE model [57]. The indentation is simulated by ABAQUS software at the same depth from experiment. The applied displacement force is added. Mechanical parameters of $\mathrm{CH}$ phase are listed in Table 3.

\section{[TABLE 3]}

As in the reference of Asroun et al. [59], an elastic perfectly plastic material model with Von Mises yield criterion $\sigma_{\mathrm{y}}(\mathrm{GPa})$ is assumed for the indented materials. The yield stresses are considered to be equal to $0.198 \mathrm{GPa}$ for LD C-S-H, 0.347 GPa for HD C-S-H and 0.440 GPa for $\mathrm{CH}$.

\subsubsection{Stress distribution and deformed zones in simulation}

Comparison of P-h curves using the forced displacement mode and the forced loading mode are the same, here we use the former. Simulation parameters are set as: elastic moduli are separately 45.46 GPa (DFT+RVH method) and $39.88 \mathrm{GPa}$ (experiment). The region range of Poisson ratio $v$ is 0.25-0.30. The yield stress can be averaged by the experimental data [60] and the simulated data [61], which is $0.44 \mathrm{GPa}$. The contact friction is set about 0.6 [32]. Stress distribution and deformed 
displacement zones of $\mathrm{CH}$ are in Fig.13.

\section{[FIGURE 13]}

As in Fig.13, after unloading, the maximum residual stress on the ideal contact condition distributes just below the indenter, while on the friction condition it distributes around the top of indenter in Fig.13 a) and the displacement below the indenter is not too large in Fig.13 b).

The LD C-S-H phase can be modeled as a cohesive-frictional plastic and linear elastic material [60]. The forced displacement method is used, as mentioned above. From the load-depth curve of LD C-S-H phase nano-indentation experiment, the pressure is about $1.5 \mathrm{mN}$ and the maximum indent depth is about $441.79 \mathrm{~nm}$, the representative curve of LD C-S-H is as in section 4.3. The yield stress can be averaged by the experimental data [60] and the simulation [61], which is $0.198 \mathrm{GPa}$. The LD C-S-H parameters were separately set as follows: elastic modulus E are separately 18.22 GPa (by the Self-Consistent Scheme, v=0.25), 29.78 GPa (by the Mori-Tanaka Scheme, $v=0.25$ ) and $17.35 \mathrm{GPa}$ (nano-indentation experiment). The region range of Poisson's ratio $\mu$ is $0.20-0.25$ and the contact friction is about 0.6 [32]. Stress distribution and deformed displacement zones of LD C-S-H are shown in Fig.14.

\section{[FIGURE 14]}

As is in Fig.14, the maximum residual stress after unloading on the ideal contact condition distributes just below the indenter, while the maximum residual stress after unloading on the friction condition distributes around the top of indenter and the residual stress below the indenter is not too large.

From the representative load-depth curve of HD C-S-H phase nano-indentation experiment, the pressure is about $1.5 \mathrm{mN}$ and the maximum indent depth of HD C-S-H phase is about $278.08 \mathrm{~nm}$, the representative curve of HD C-S-H is as in section 4.3. Similarly, the HD C-S-H parameters were separately set as follows: elastic modulus E are separately $31.63 \mathrm{GPa}$ (by the Self-Consistent Scheme, v=0.25), 37.71 GPa (by the Mori-Tanaka Scheme, v=0.25) and $32.70 \mathrm{GPa}$ (nano-indentation experiment). The region range of Poisson ratio $\mu$ is $0.20-0.25$, and the yield stress 
in the equation (5) is $0.347 \mathrm{GPa}$. According the reference [32], the contact friction is about 0.6. Stress distribution and deformed displacement zones of HD C-S-H are in Fig.15.

\section{[FIGURE 15]}

As is shown in Fig.15, the maximum residual stress after unloading on the ideal contact condition distributes just below the indenter, while the maximum residual stress after unloading on the friction condition distributes around the top of indenter and the residual stress below the indenter is not too large.

\subsubsection{Elastic modulus analysis and P-h curve in simulation}

Using ABAQUS software, under the loading force of $1.5 \mathrm{mN}$, the comparison of experimental and simulated P-h curves is in Fig.16.

\section{[FIGURE 16]}

As in Fig.16, the simulated unloading part is close to the representative experimental part. It can be seen that, the smaller the Poisson's ratio is, the smaller the slope of unloading curve is. Comparing the purely elastic unloading curve of $\mathrm{CH}$ phase in Fig.16, it can be seen that results obtained with experimental data from DFT $+\mathrm{RVH}$ method is very consistent with experimental results, which verifies the reliability of simulation method.

Similarly, the comparison of experimental and simulated unloading P-h curves of LD C-S-H phase is in Fig.17.

\section{[FIGURE 17]}

As is shown in Fig.17, we can see that the simulated unloading part is close to the representative experimental part. It can be seen that, the smaller Poisson's ratio is, the smaller the slope of unloading curve is. Comparison of purely elastic unloading curve of LD C-S-H phase in Fig.6.17 b), we can see that, the Mori-Tanaka Scheme (29.78 GPa, v=0.25) and the Self-Consistent 
Scheme (18.22 GPa, v=0.25) are very consistent with experimental results (17.35 GPa), which verifies the reliability of both simulation method.

Moreover, using ABAQUS software, under the loading force of $1.5 \mathrm{mN}$, the comparison of experimental and simulated unloading P-h curves of HD C-S-H phase is shown in Fig.18.

\section{[FIGURE 18]}

As is in Fig.18, we can see that the simulated unloading part is close to the representative experimental part. It can be seen that, the smaller Poisson's ratio is, the smaller the slope of unloading curve is. Comparison of purely elastic unloading curve of HD C-S-H phase is in Fig.18 b), we can see that, the Mori-Tanaka Scheme (37.71 GPa, v=0.25) and the Self-Consistent Scheme (31.36 GPa, v=0.25) are very consistent with experimental results $(32.70 \mathrm{GPa})$, which verifies the reliability of simulation method. This indicates that the selected simulation parameters are reliable, which thus provides the basis and parameters for the multi-scale simulation [4,5] and the meso-scale mechanical behavior of cementitious composites [62].

\section{Conclusion}

At nano-scale, $\mathrm{CH}$ crystal is calculated by DFT method (GGA approximation) and the homogenized elastic modulus is obtained, then the monolithic C-S-H structure with the chemical formula: $\left.(\mathrm{CaO})_{1.67}\left(\mathrm{SiO}_{2}\right)\left(\mathrm{H}_{2} \mathrm{O}\right)_{1.75}\right)$ is simulated during the stretch process at strain rate $10^{-3} \mathrm{ps}^{-1}$ by MD method using ClayFF field. The homogenized elastic modulus of $\mathrm{CH}$ structure is obtained by DFT and Reuss-Voigt-Hill estimation and elastic modulus of LD and HD C-S-H are assessed by the monolithic C-S-H. Then at micro scale, FEM is used to simulate the nano-indentation process and Young moduli of $\mathrm{CH}$ and $\mathrm{C}-\mathrm{S}-\mathrm{H}$ phases are determined by the load-depth curve. Comparison of the simulated and experimental P-h curve is analyzed. Conclusions are as:

1) Based on DFT method and Reuss-Voigt-Hill approximation, Young's modulus of $\mathrm{CH}$ is estimated to be $45.459 \mathrm{GPa}$, which is close to the result of $45.946 \mathrm{GPa}$ given by Laugesen, the result of 52.4 GPa found by Speziale et al., 44.69 GPa by Kerisit et al., 46.58 GPa by Holuj et al. The relative errors on $\mathrm{C}_{\mathrm{ij}}$ coefficients and Young's modulus are acceptable.

2) The load-depth curve of $\mathrm{CH}$ is simulated by FEM modeling. Besides, the load-depth curves 
based on the DFT+RVH method (45.459 GPa, by LDA method) is close to the experimental result of $39.88 \mathrm{GPa}$ found by nanoindentation testing, which verifies the reliability of the simulation method.

3) The averaged modulus of the monolithic C-S-H in three directions is $60.95 \mathrm{GPa}$ under strain rate of $10^{-3} \mathrm{ps}^{-1}$ at $300 \mathrm{~K}$. As all the three directions are rather the same, which suggests the model is amorphous. The monolithic C-S-H structure with the size of about $5 \mathrm{~nm}$ enables to evaluate elastic modulus of LD C-S-H and HD C-S-H: 18.11 GPa and 31.45 GPa, using the Self-Consistent Scheme, which is close to the value of nano-indentation experiment by Constantinides [27].

4) For $\mathrm{CH}, \mathrm{LD} \mathrm{C}-\mathrm{S}-\mathrm{H}$ and HD C-S-H phases in nano-indentation experiment, the averaged Young's moduli are respectively equal to $44.7 \pm 4.5 \mathrm{GPa}, 22.35 \pm 2.7 \mathrm{GPa}$ and $33.52 \pm 3.6 \mathrm{GPa}$, which is close to the references values of $\mathrm{CH}(40.3 \pm 4 \mathrm{GPa}$ by Constantinides and $36 \pm 3$ GPa by Acker), LD C-S-H (18.2 \pm 4.2 GPa by Constantinides and $20 \pm 2$ GPa by Acker) and HD C-S-H (29.4 \pm 2.4 GPa by Constantinides and $31 \pm 4 \mathrm{GPa}$ by Acker).

5) For LD C-S-H and HD C-S-H phases, the purely elastic unloading curves simulated are very consistent with experimental data, which is within an acceptable deviation extent thus verifies the reliability of simulation methods used. This indicates that the selected simulation parameters is reliable, which thus provides the basis and parameters for the multi-scale simulation.

In all, the simulation method of DFT and RVH estimation provides the initial parameters to obtain the mechanical properties from element cell at the nano-scale to polycrystals at micro-scale. The up-scaling of the obtained properties at the atomic level connects the atomic modeling to continuum models by using relevant input from small level, carrying thus the information of intrinsic nano-scale features.

\section{Acknowledgements}

The authors acknowledge the financial support provided by China Scholarship Council (CSC). The authors are grateful for the assistance in SEM observations and EDS analysis of the staff of the CMEBA facility (ScanMAT, UMS 2001 CNRS University of Rennes 1) which received a financial support from the Région Bretagne and European Union ( CPER-FEDER 2007-2014) 


\section{References}

[1] Maekawa K, Ishida T, Kishi T. Multi-scale modeling of concrete performance. Journal of Advanced Concrete Technology 2003, 1(2): 91-126.

[2] Liu W K, Karpov E G, Park H S.. Nano mechanics and materials: theory, multiscale methods and applications. John Wiley \& Sons, 2006.

[3] Fish J. Bridging the scales in nano engineering and science. Journal of Nanoparticle Research, 2006, 8(5): 577-594.

[4] Kamali-Bernard S, Bernard F. Effect of tensile cracking on diffusivity of mortar: 3D numerical modelling. Computational Materials Science 2009, 47:178-185

[5] Bernard F, Kamali-Bernard S, Prince W. 3D multi-scale modelling of mechanical behaviour of sound and leached mortar.Cement and Concrete Research 2008, 38:449-458

[6] Curtin WA, Miller RE. Atomistic/continuum coupling in computational materials science. Modeling and Simulation in Materials Science and Engineering 2003, 11: 33-68.

[7] Fu J, Sun H. An ab initio force field for predicting hydrogen storage in IRMOF materials. Journal of Physical Chemistry C 2009, 113(52): 21815-21824.

[8] Lu G, Kaxiras E. Overview of Multiscale Simulations of Materials, Handbook of Theoretical and Computational Nanothechnology, Vol. X: 1-33, edited by M. Rieth and W. Schommers.,2005.

[9] Ye G.. Experimental study and numerical simulation of the development of the microstructure and permeability of cementitious materials.Doctoral dissertation, TU Delft, Delft University of Technology, 2003.

[10] Vandamme M, Ulm FJ. Nanoindentation investigation of creep properties of calcium silicate hydrates. Cement and Concrete Research 2013, 52: 38-52.

[11] Oliver WC, Pharr GM. An improved technique for determining hardness and elastic modulus using load and displacement sensing indentation experiments. Journal of materials research 1992,7(06): 1564-1583.

[12] Ulm F J, Vandamme M, Bobko C, Alberto Ortega J, Tai K, Ortiz C. Statistical indentation techniques for hydrated nanocomposites: concrete, bone, and shale.Journal of the American Ceramic Society 2007, 90(9): 2677-2692.

[13] Sorelli L, Constantinides G, Ulm F J, Toutlemonde F. The nano-mechanical signature of ultra high performance concrete by statistical nanoindentation techniques. Cement and Concrete Research 2008, 38(12):1447-1456.

[14] Riedel R, Handbook of Ceramic Hard Materials, Weinheim: Wiley-VCH, 2000.

[15] Geiger M, Kleiner M, Eckstein R. Microforming. CIRP Annals-Manufacturing Technology 2001,50(2): 445-462.

[16] Gilman JJ.,Chemistry and Physics of Mechanical Hardness, Hoboken: John Wiley \& Sons, 2009.

[17] Al-Rub RKA, Voyiadjis GZ. Analytical and experimental determination of the material intrinsic length scale of strain gradient plasticity theory from micro-and nano-indentation experiments. International Journal of plasticity 2004, 20: 1139-1182.

[18] Tho K K, Swaddiwudhipong S, Hua J, Liu Z S. Numerical simulation of indentation with size effect. Materials Science and Engineering: A 2006, 421(1-2): 268-275.

[19]Raki L, BeaudoinJ,, Alizadeh J, Makar R,., \& Sato T. Cement and concrete nanoscience and nanotechnology. 
Materials 2010, 3, 918-942.

[20] Kwan S, LaRosa Thompson J., Grutzeck MW. Structures and Phase Relations of Aluminum - Substituted Calcium Silicate Hydrate. Journal of the American Ceramic Society 1996, 79(4): 967-971.

[21] Taylor HFW， Howison JW. Relationship between calcium silicates and clay minerals. Clay Mineral Bulletin 1956, 31:98-111.

[22] Taylor HFW.. Cement chemistry. (2nd Edition), Thomas Telford, London, 2007.

[23] Allen AJ, Thomas JJ, Jennings HM. Composition and density of nanoscale calcium-silicate-hydrate in cement. Nature materials 2007, 6(4): 311-316.

[24] Jennings HM. A model for the microstructure of calcium silicate hydrate in cement paste. Cement and Concrete Research 2000, 30(1): 101-116.

[25] Hou, D, et al.. Calcium silicate hydrate from dry to saturated state: Structure, dynamics and mechanical properties. Acta Materialia 2014, 67: 81-94.

[26] Al-Ostaz A, Wu W, Cheng A D, Song C R. A molecular dynamics and microporomechanics study on the mechanical properties of major constituents of hydrated cement. Composites Part B: Engineering 2010, 41(7): 543-549.

[27] Constantinides, G., Ulm FJ. The effect of two types of C-S-H on the elasticity of Cement-based materials: Results from nanoindentation and micromechanical modeling. Cement and Concrete Research, 2003 (34):67-80.

[28] Bernard F., Kamali-Bernard S.. Predicting the evolution of mechanical and diffusivity properties of cement pastes and mortars for various hydration degrees - A numerical simulation investigation. Computational Materials Science 2012; $61: 106-115$

[29] Gao Y, De Schutter G, Ye G, Tan Z, Wu K. The ITZ microstructure, thickness and porosity in blended cementitious composite: Effects of curing age, water to binder ratio and aggregate content. Composites Part B: Engineering 2014, 60: 1-13.

[30] Abidi S, Joliff Y, Favotto C. Impact of perlite, vermiculite and cement on the Young modulus of a plaster composite material: Experimental, analytical and numerical approaches. Composites Part B: Engineering 2016, 92: 28-36.

[31] Keinde, D.. Etude du béton à l'échelle mesoscopique: simulation numérique et tests de micro-indentation, Doctoral dissertation, INSA de Rennes, 2014. (In French).

[32] Constantinides G, Ulm FJ. The effect of two types of CSH on the elasticity of cement-based materials: Results from nanoindentation and micromechanical modeling.Cement and Concrete Research 2004, 34(1), 67-80.

[33] Speziale S, Reichmann H J, Schilling F R, Wenk H R, Monteiro P J M. Determination of the elastic constants of portlandite by Brillouin spectroscopy.Cement and Concrete Research 2008, 38(10):1148-1153.

[34] MULLER, Arnaud Charles Albert. Characterization of porosity \& CSH in cement pastes by 1H NMR. 2014. Thèse de doctorat. École Polytechnique Fédérale de Lausanne.

[35] Hohenberg P, Kohn W, Inhomogeneous electron gas. Physical Review B, 1964, 136(3B), B 864-871.

[36] Segall M D, Lindan P J, Probert M A, Pickard C J, Hasnip P J, Clark S J, Payne M C. First-principles 
simulation: ideas, illustrations and the CASTEP code. Journal of Physics: Condensed Matter 2002, 14(11): 2717-2744.

[37] Perdew JP, Burke K, Ernzerhof M. Generalized gradient approximation made simple.Physical Review Letters 1996, 77(18): 3865-3868.

[38] Ceperley DM, Alder BJ. Ground state of the electron gas by a stochastic method..Physical Review Letters 1980, 45(7): 566-569.

[39] Perdew JP, Zunger A. Self-interaction correction to density-functional approximations for many-electron systems. Physical Review B 1981, 23(10): 5048-5079.

[40] Aaeid A. Études ab initio et dynamique moléculaire des propriétés structurales et thermodynamiques de la calcite et la witherite sous hautes pressions, 2010, PhD Thesis, l'Université des Sciences et Technologies de Lille, France. (In French)

[41] Fu J, Bernard F, Kamali-Bernard S. Assessment of the elastic properties of amorphous Calcium Silicates Hydrates (I) and (II) structures by Molecular Dynamics Simulation, Molecular Simulation 2017, 44(6):1-15.

[42] Cygan RT, Liang JJ, Kalinichev AG. Molecular models of hydroxide, oxyhydroxide, and clay phases and the development of a general force field. Journal of Physical Chemistry B 2004, 108(4): 1255-1266.

[43] Plimpton S., Thompson A., Crozier P. Molecular Dynamics Simulations from SNL's Large-scale Atomic/Molecular Massively Parallel Simulator (LAMMPS).

[44] Heinz P. Continuum mechanics modeling of composite materials. Habilitationsschrift, TU-Wien, 2003

[45] Lu YC, Shinozaki DM. Effects of substrate constraint on micro-indentation testing of polymer coatings. Materials Science and Engineering A 2005, 396(1-2): 77-86.

[46] Shi Z, Feng X, Huang Y, Xiao J, Hwang K C. The equivalent axisymmetric model for Berkovich indenters in power-law hardening materials. International Journal of Plasticity 2010, 26(1): 141-148.

[47] Sneddon IN. The relation between load and penetration in the axisymmetric Boussinesq problem for a punch of arbitrary profile.International Journal of Engineering Science, 1965, 3(1), 47-57.

[48] TABOR D. A simple theory of static and dynamic hardness. Proceedings of the Royal Society of London A:

Mathematical, Physical and Engineering Sciences. The Royal Society, 1948:247-274.

[49] Nye JF. Physical Properties of Crystals, Clarendon Press, Oxford, 1964.

[50] Hill R. The elastic behaviour of a crystalline aggregate. Proceedings of the Physical Society. Section A 1952, 65(5): 349 .

[51] Wu Z, Zhao E, Xiang H P, Hao X F, Liu X J, Meng J. Crystal structures and elastic properties of superhard IrN2 and IrN3 from first principles. Physical Review B 2007, 76(5): 054115.

[52] Fu J, Bernard F, Kamali-Bernard S. Multiscale Modeling and Mechanical Properties of Zigzag CNT and Triple-Layer Graphene Sheet Based on Atomic Finite Element Method. Journal of Nano Research 2015,33,:92-105.

[53] Fu J, Bernard F, Kamali-Bernard S. First-principles calculations of typical anisotropic cubic and hexagonal structures and homogenized moduli estimation based on the Y-parameter: Application to $\mathrm{CaO}, \mathrm{MgO}, \mathrm{CH}$ and Calcite $\mathrm{CaCO}_{3}$. Journal of Physics and Chemistry of Solids 2017,101:74-89.

[54] Laugesen JL. Density functional calculations of elastic properties of portlandite, $\mathrm{Ca}(\mathrm{OH}) 2$. Cement and Concrete Research 2005, 35(2):199-202. 
[55] Constantinides G. Invariant mechanical properties of calcium-silicate-hydrates (CHS) in cement-based materials: instrumented nanoindentation and microporomechanical modeling, Doctoral dissertation, Massachusetts Institute of Technology, 2006.

[56] Acker P, Ulm FJ, Bazant ZP, Wittmann, FH (Eds); micromechanical analysis of creep and shrinkage mechanisms. In : Creep, Shrinkage and durability Mechaninics of Concrete and other quasi-brittle Material, Elsiever, Oxford, UK, Cambridge, MA, 2001: 15-25.

[57] Ali D, Sen S. Finite element analysis of the effect of boron nitride nanotubes in beta tricalcium phosphate and hydroxyapatite elastic modulus using the RVE model. Composites Part B: Engineering 2016, 90: 336-340.

[58] Fu J, Bernard F, Kamali-Bernard S. Nanoscale modeling and elastic properties of Portlandite and Graphene based on Atomic Finite Element Method.Applied Mechanics and Materials 2015, 711:137-142.

[59] Asroun, Nasser, and Aissa Asroun. Nanoindentation simulation of concrete with various indenter forms and yield strengths. International Journal of Pure and Applied Sciences and Technology,2013,16(2): 75-84.

[60] Vandamme M. The Nanogranular Origin of Concrete Creep: A Nanoindentation investigation of microstructure and fundamental properties of Calcium-Silicate-Hydrates, Ph.D. Thesis, Massachusetts Institute of Technology, Cambridge, MA, 2008.

[61] Sarris E, Constantinides G. Finite element modeling of nanoindentation on C-S-H: Effect of pile-up and contact friction. Cement and Concrete Composites 2013, 36, 78-84.

[62] Niknezhad D, Raghavan B, Bernard F, Kamali-Bernard S. Towards a realistic morphological model for the meso-scale mechanical and transport behavior of cementitious composites. Composites Part B: Engineering 2015, 81: 72-83. 


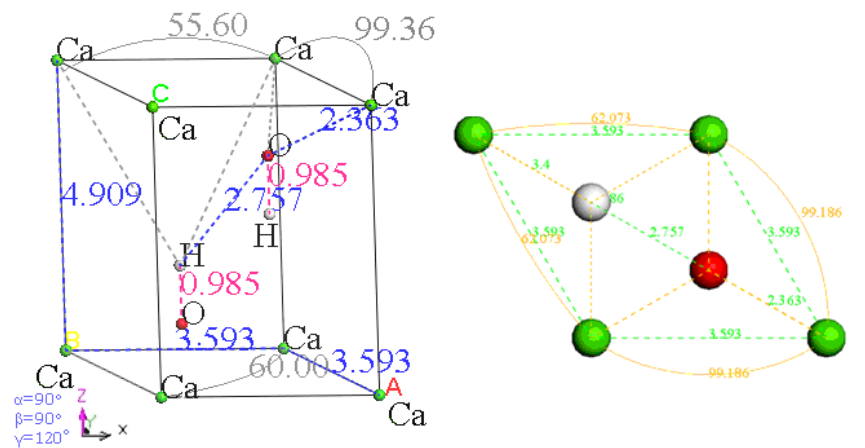

Fig.1 Modeling parameters of $\mathrm{CH}$ crystal 


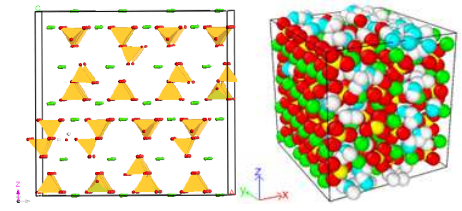

(a) Model of $2.7 \times 2.2 \times 2.3 \mathrm{~nm}^{3}$

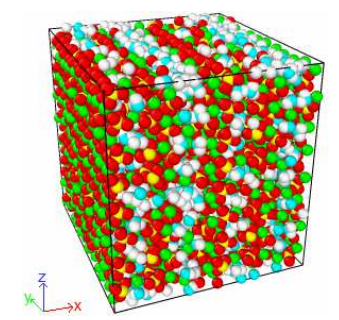

(b) Model of $5.4 \times 4.4 \times 4.6 \mathrm{~nm}^{3}$

(Atom types: red-Ow + white-Hw $\rightarrow$ water molecule $\left(\mathrm{H}_{2} \mathrm{O}\right)$; red-O; green -Ca; purple-Ca; yellow-Si)

Fig.2 Construction of a monolithic "Globule" C-S-H structure about $5 \mathrm{~nm}$ 


\section{ACCEPTED MANUSCRIPT}
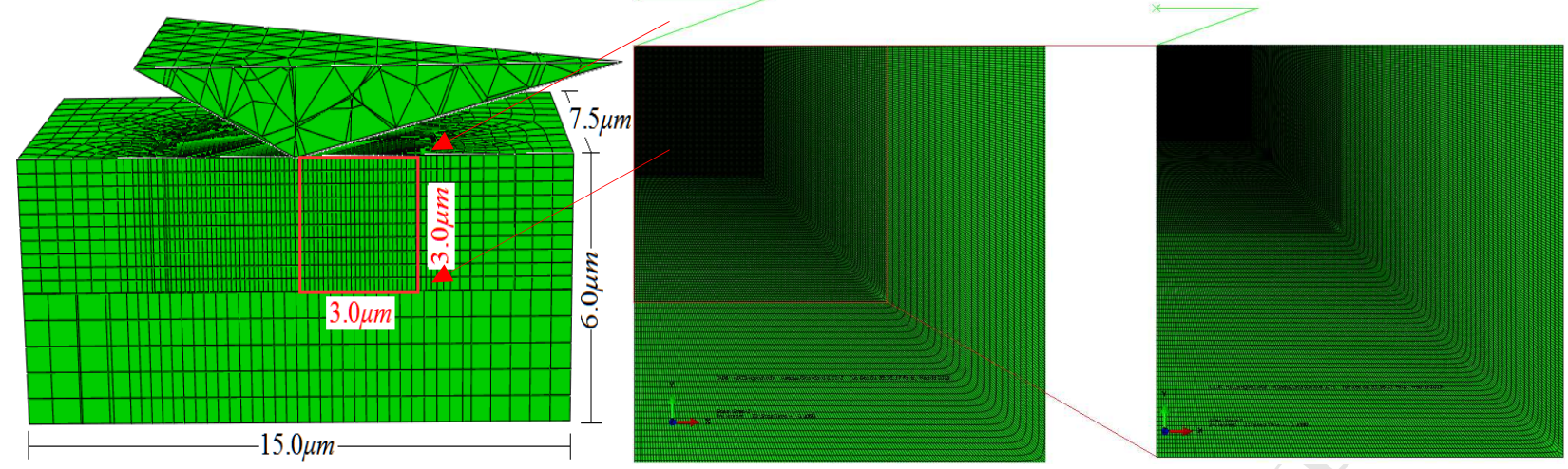

a) 3D model

b) $2 \mathrm{D}$ model with three mesh regions

c) Partial 2D model with fine mesh

Fig.3 Indentation simulation on 3D and 2D models of typical cement paste phases 




a) Nano-hardness platform

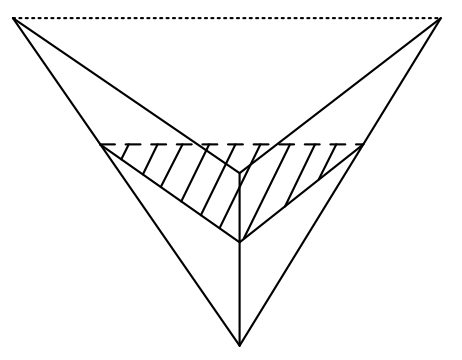

b) Berkovich diamond indenter

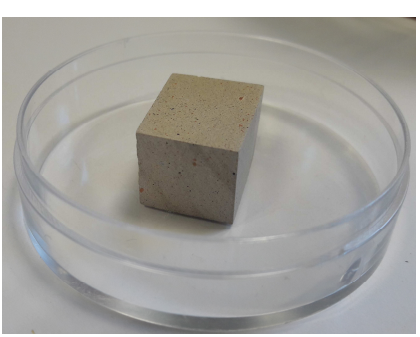

c) Cement paste sample

Fig.4 CSM instrument of INSA de Rennes used in nano-indentation experiment. 

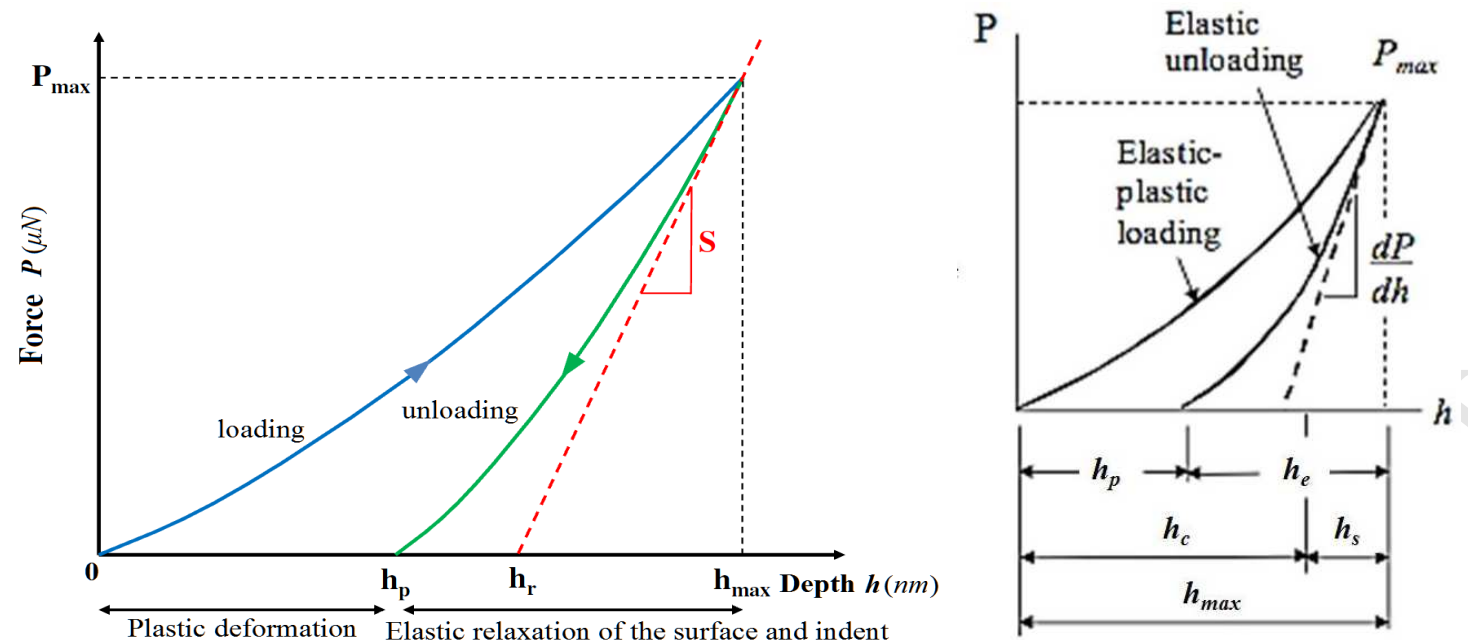

Fig.5 Typical load-depth curves in nano-indentation experiment 


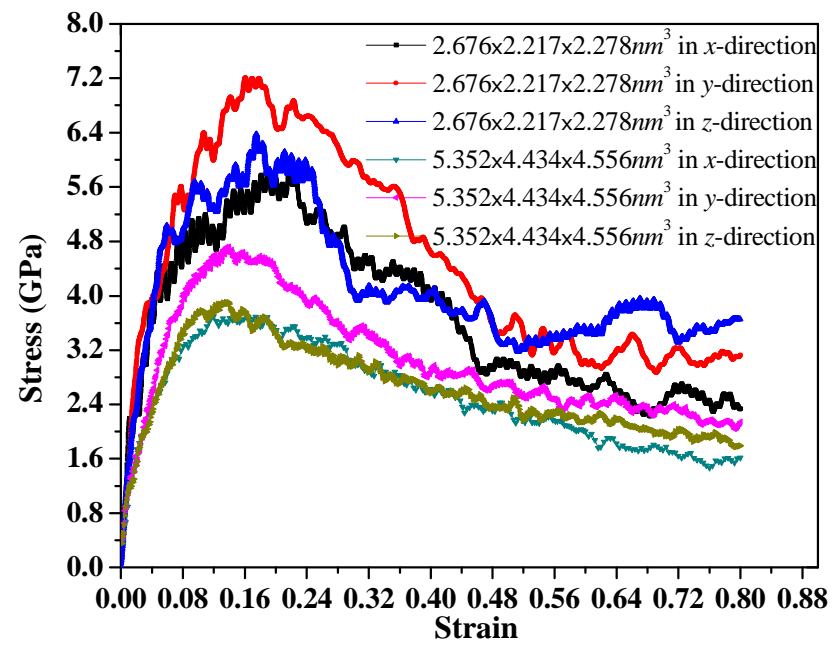

Fig.6 Comparison of two supercell C-S-H structures under various directions 


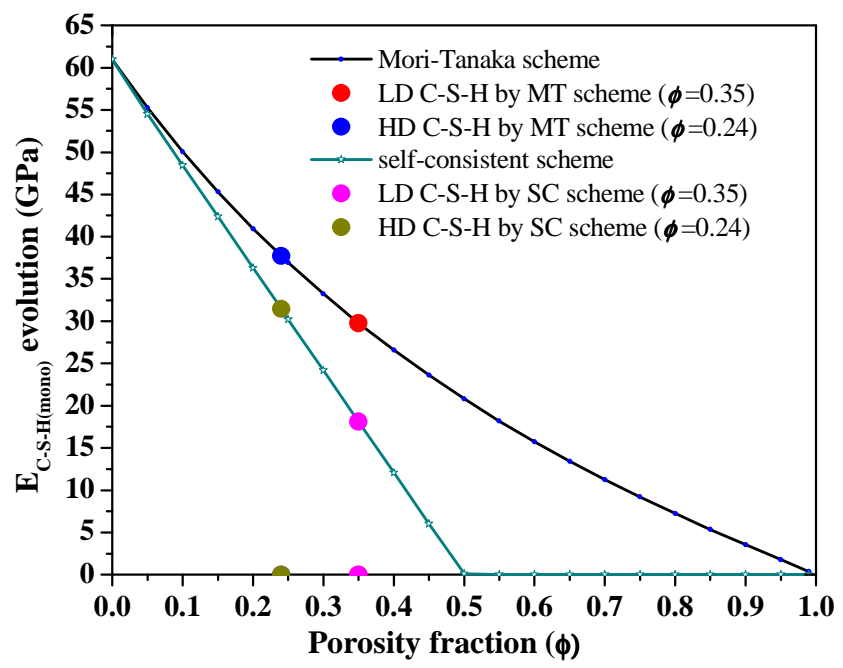

Fig.7. The elastic modulus assessment of LD and HD C-S-H using the Self-Consistent and Mori-Tanaka schemes 

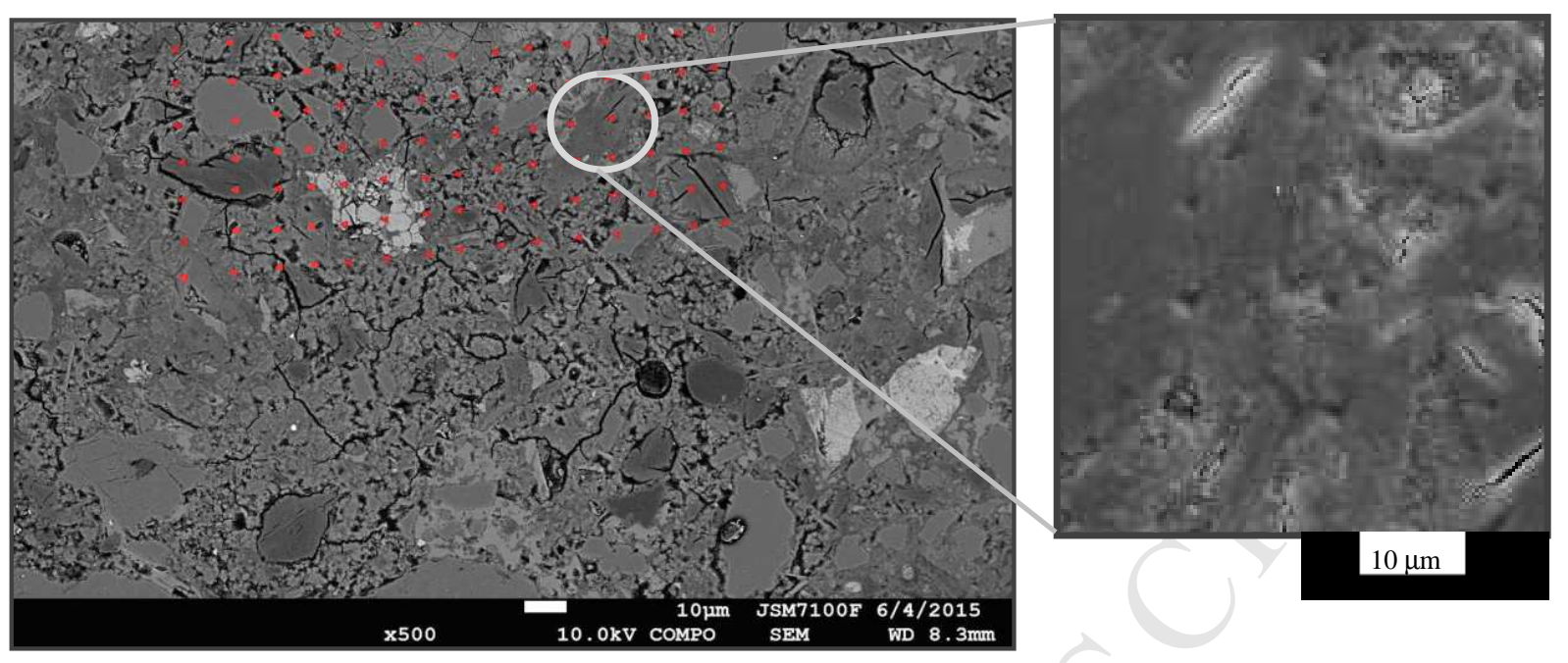

Fig.8 indentation points (in red) mapped onto one backscattered electron image (left) and a secondary electron image of one region of the indented area showing the permanent deformation left by the indent (right) 


\section{ACCEPTED MANUSCRIPT}
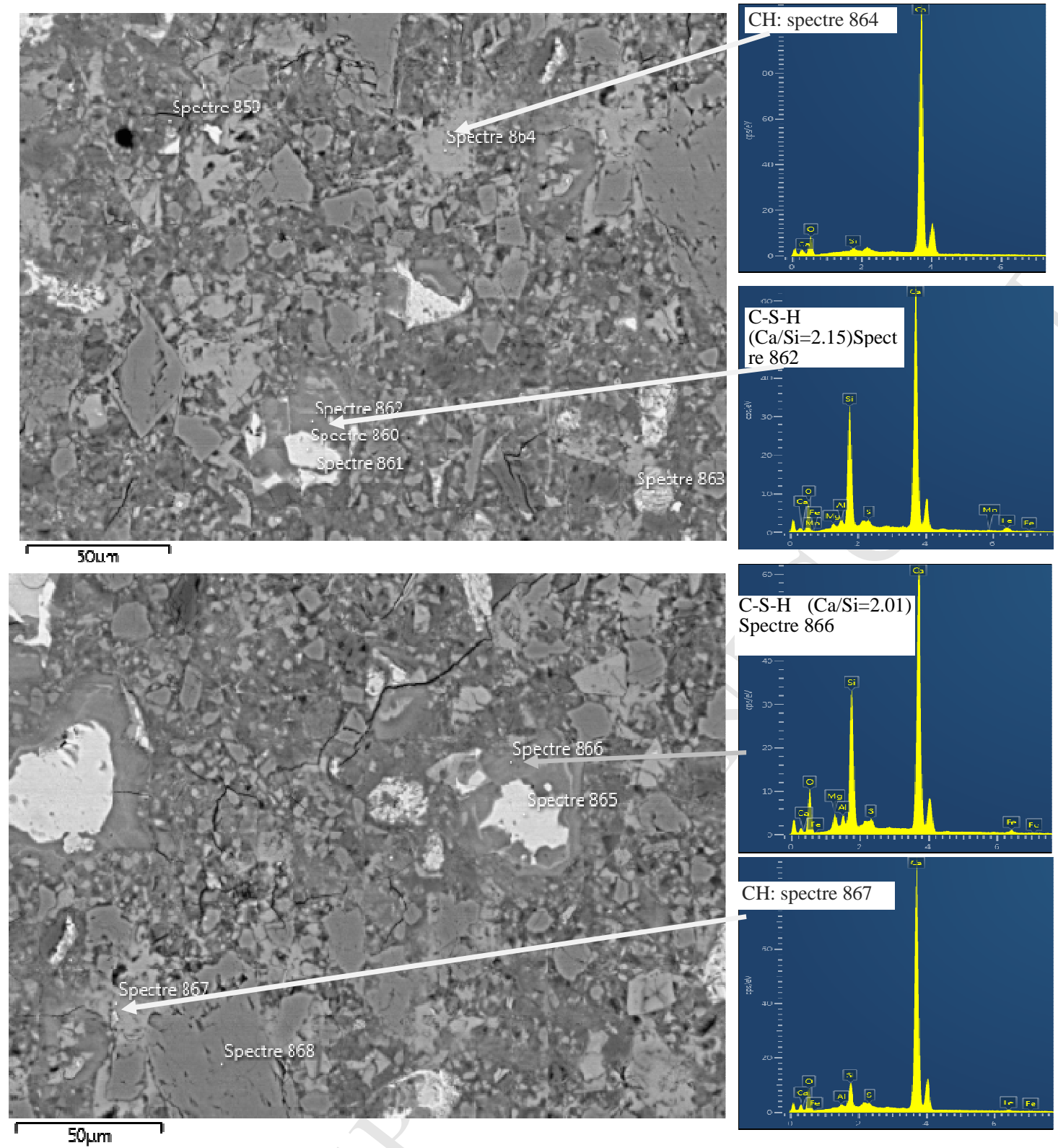

Figure 9: Backscattered electron images of different area of the specimen with EDS analysis of different points allowing the identification of portlandite $(\mathrm{CH})$ and $\mathrm{C}-\mathrm{S}-\mathrm{H}$ with $\mathrm{Ca} / \mathrm{Si}$ of about 2 . 


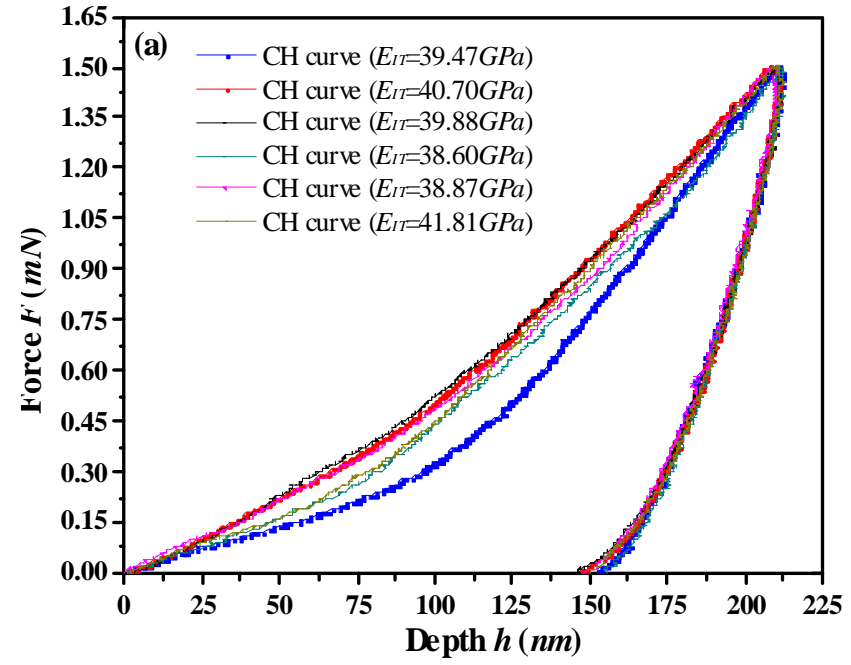

a). Typical curves of $\mathrm{CH}$ phase

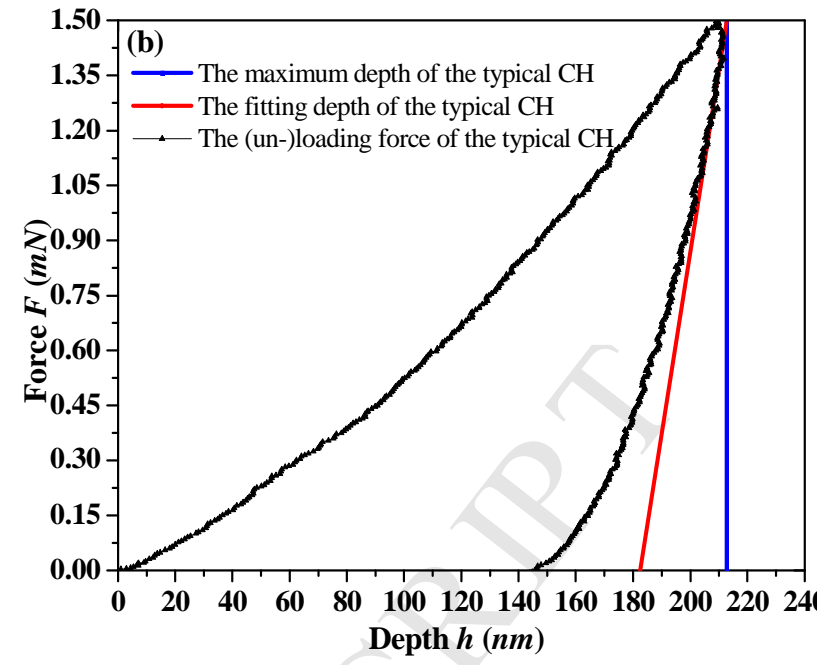

b). Representative curve of $\mathrm{CH}$ phase

Fig.10 Representative experimental curves of $\mathrm{CH}$ phase 


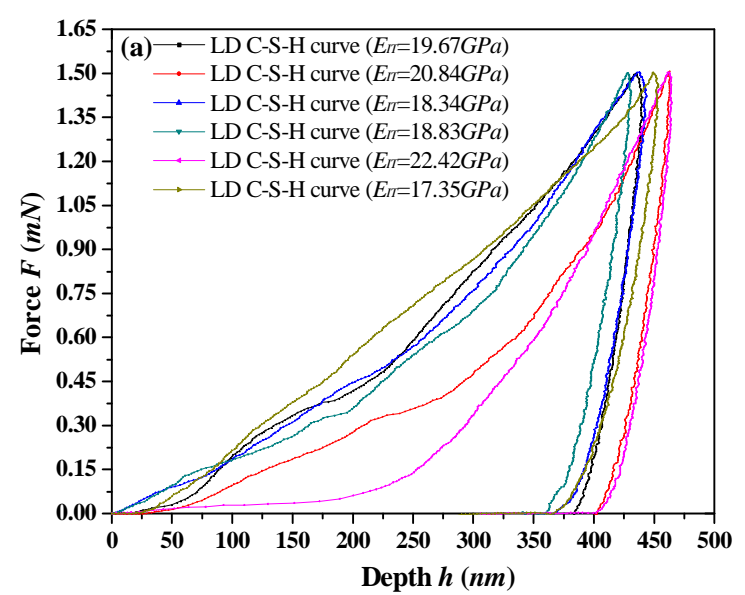

a). Typical curves of outer LD C-S-H phase

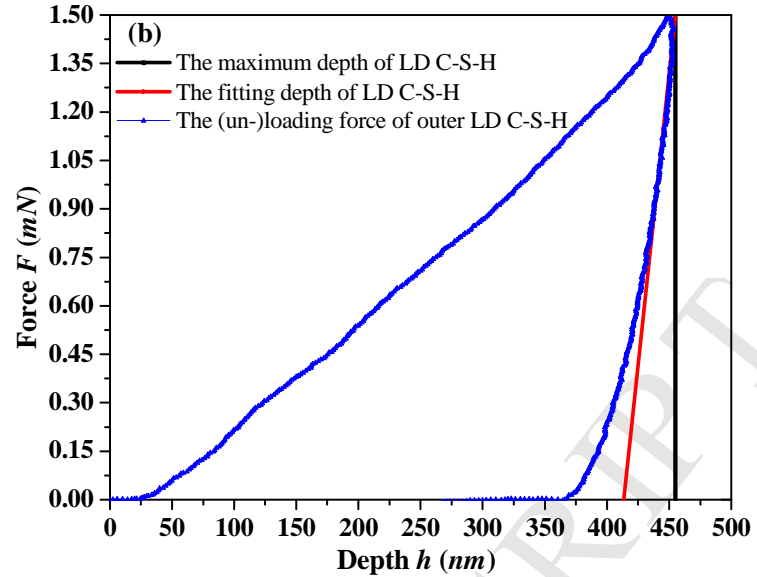

b). Representive curve of outer LD C-S-H phase

Fig.11 Representive experimental curves of outer LD C-S-H phase. 


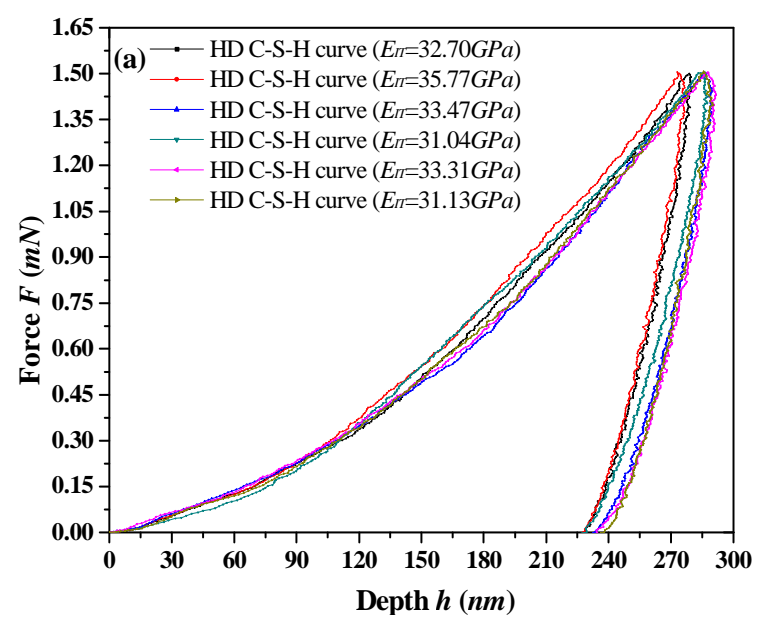

a). Typical curves of inner HD C-S-H phase

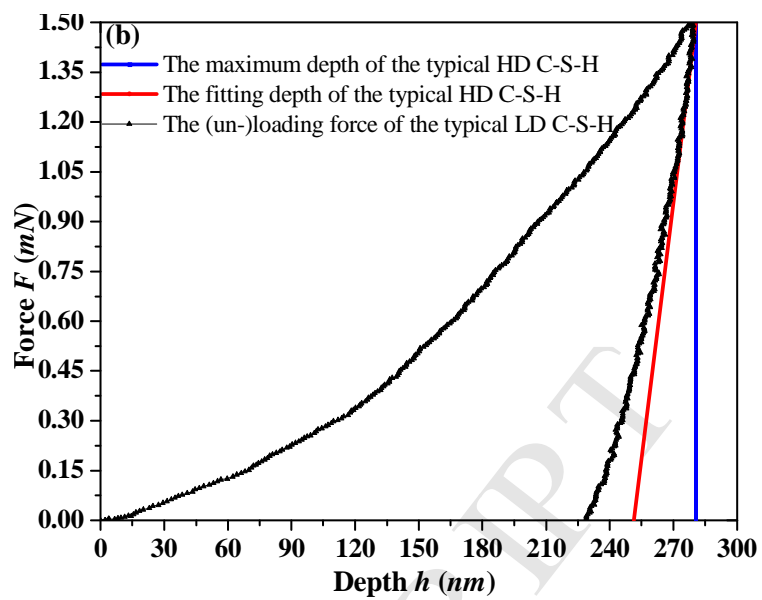

b). Representative curve of inner HD C-S-H phase

Fig.12 Representative experimental curves of inner HD C-S-H phase 


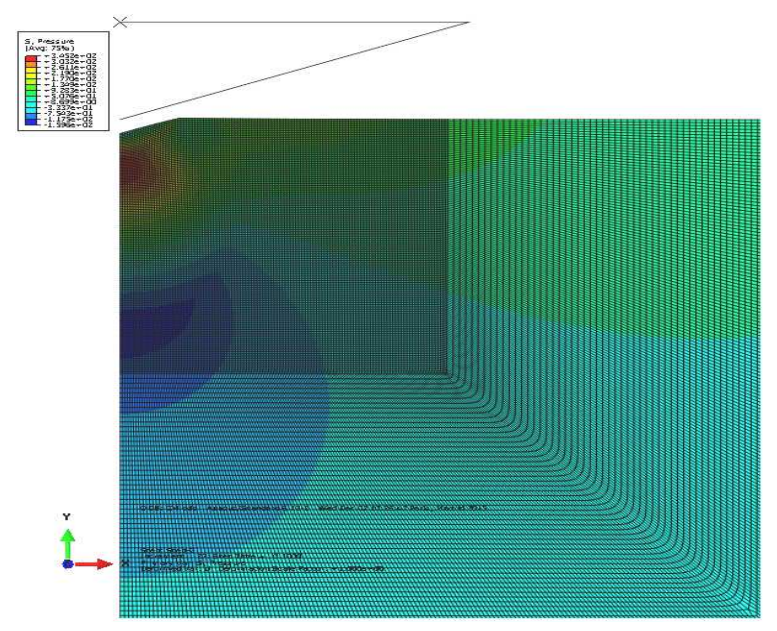

a) Stress distribution zone ( $\mathrm{f}=0.6)$

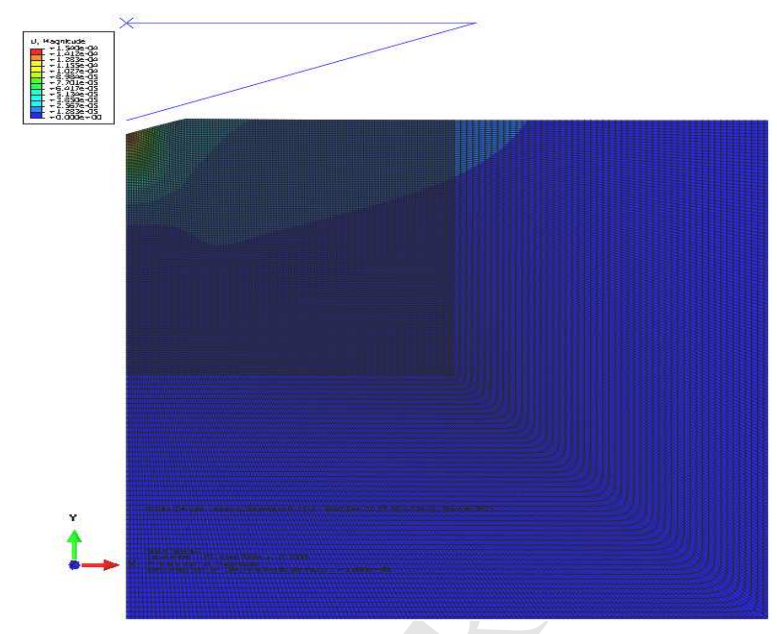

b) Deformed displacement zone ( $\mathrm{f}=0.6)$

Fig.13 Stress distribution and displacement zones of $\mathrm{CH}$ 


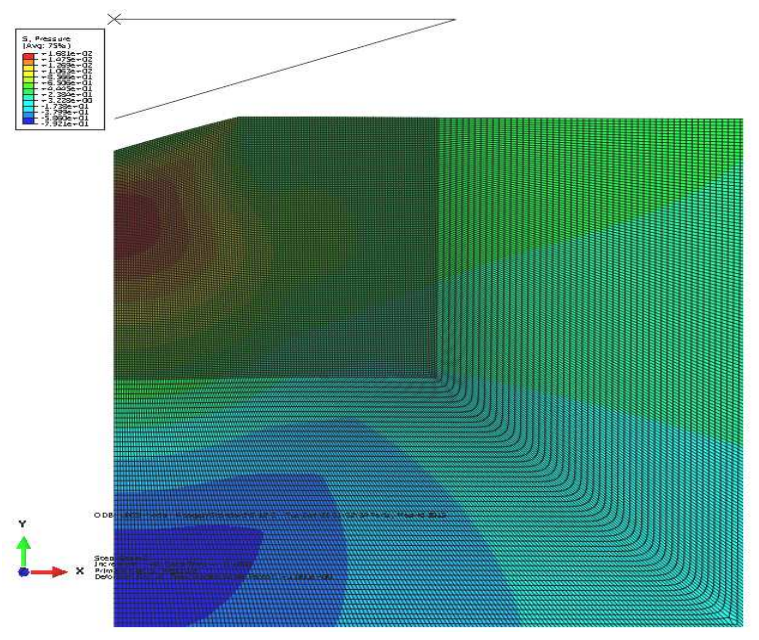

a) Stress distribution zone ( $\mathrm{f}=0.6$ )

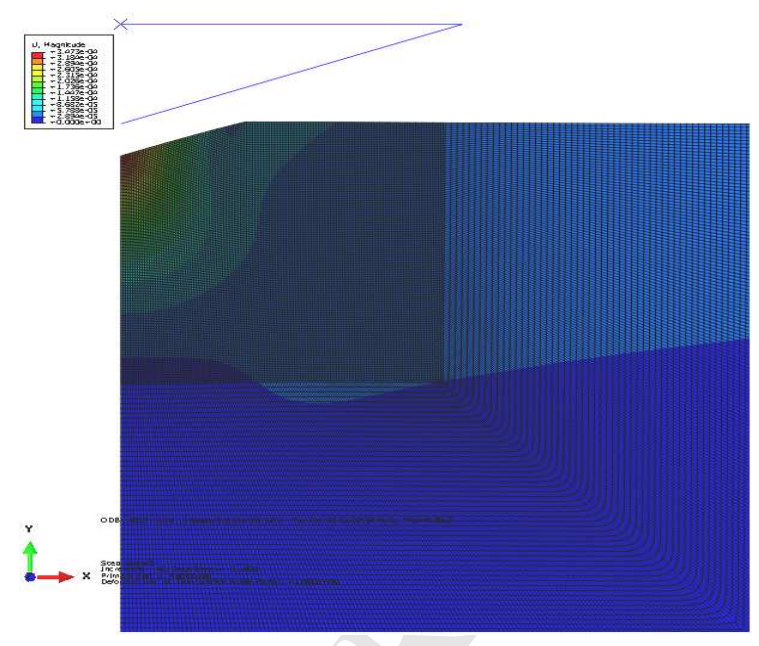

b) Deformed displacement zone ( $\mathrm{f}=0.6$ )

Fig.14 Stress distribution and displacement zones of LD C-S-H under various frictions 


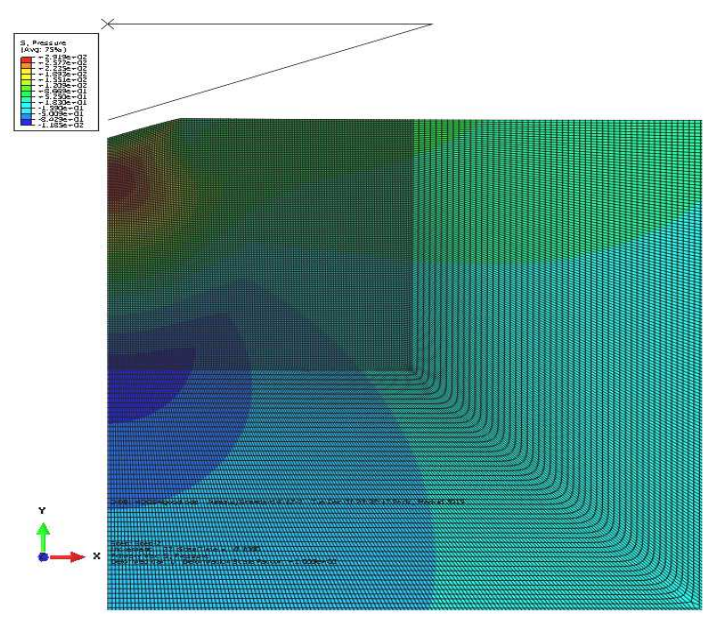

a) Stress distribution zone ( $\mathrm{f}=0.6$ )

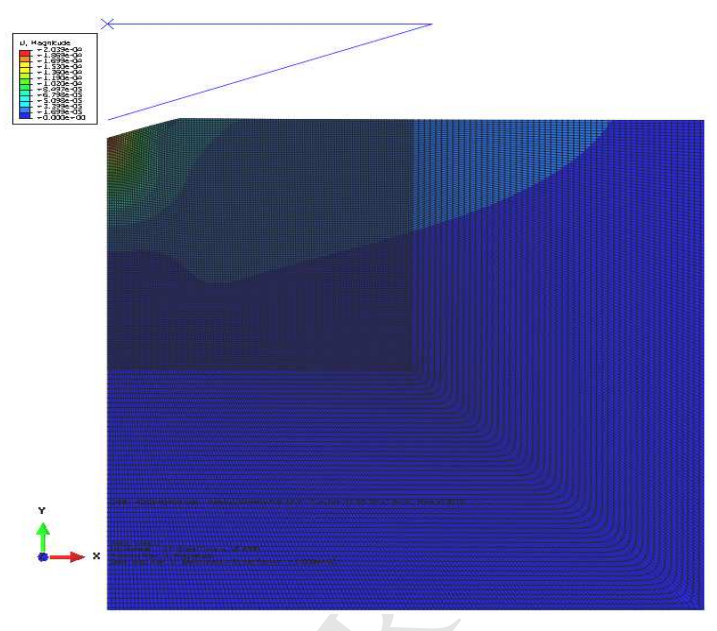

b) Deformed displacement zone ( $\mathrm{f}=0.6$ )

Fig.15 Stress distribution and displacement zones of HD C-S-H under various frictions 


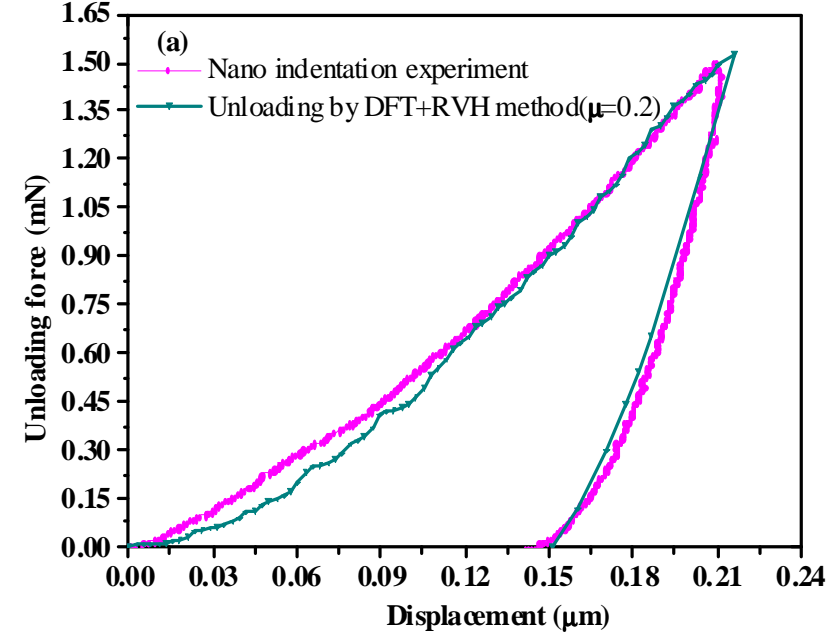

a) Comparison of experiment and DFT method

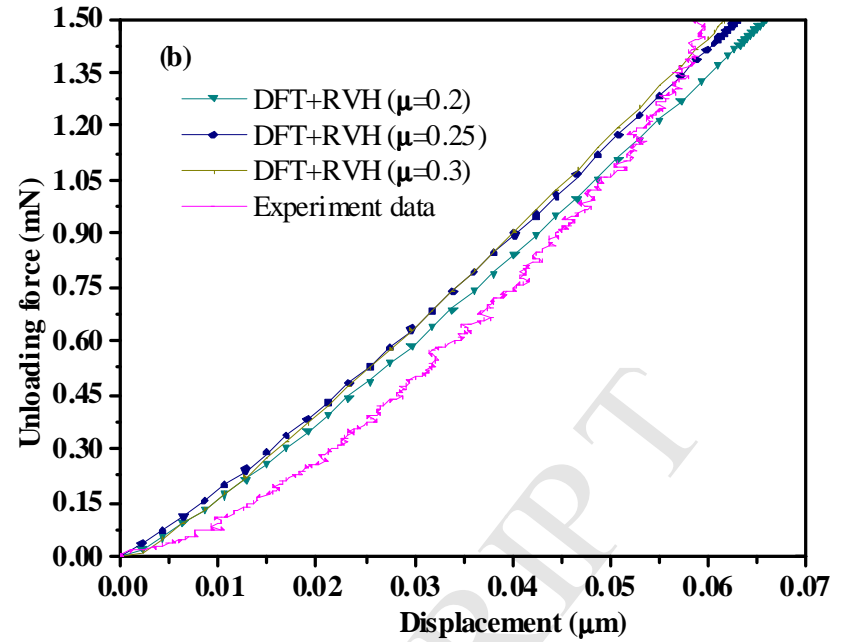

b) Unloading curves by various Poisson's ratio

Fig.16 Comparison of experimental and simulated $\mathrm{P}-\mathrm{h}$ and unloading curves of $\mathrm{CH}$ phase 


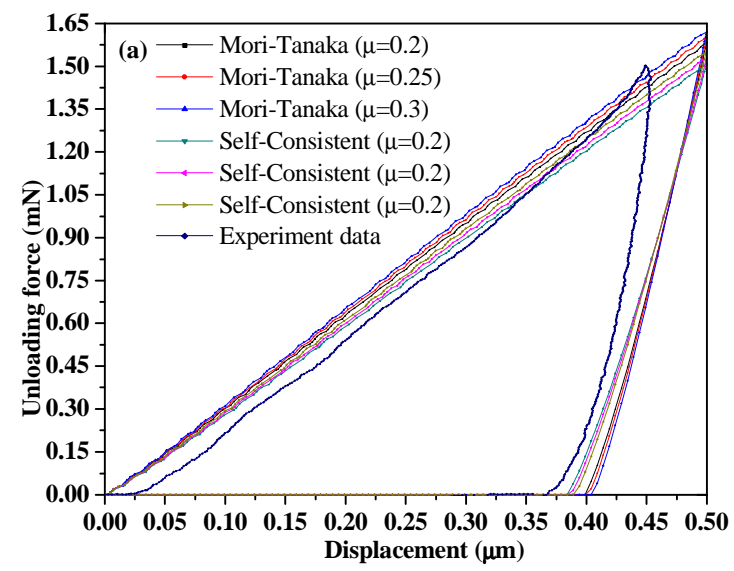

a) Comparison of experiment and MD simulation

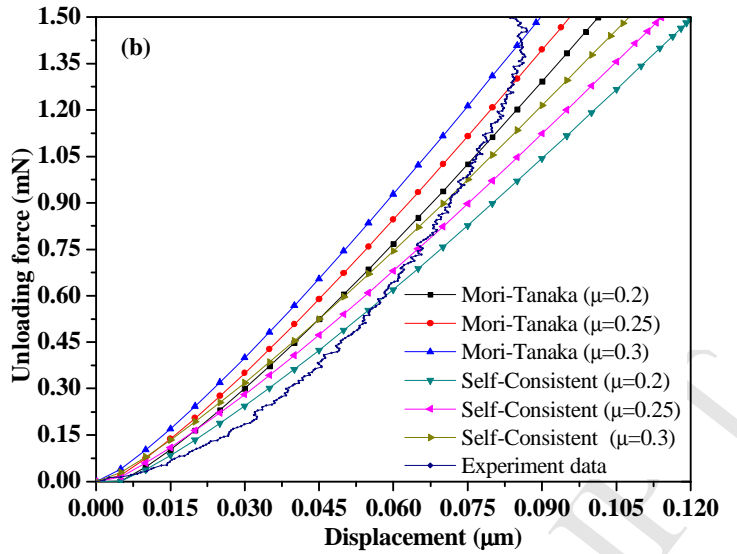

b) Unloading curves under various Poisson's ratio

Fig.17 Comparison of experimental and simulated unloading P-h curves of LD C-S-H phase 


\section{ACCEPTED MANUSCRIPT}

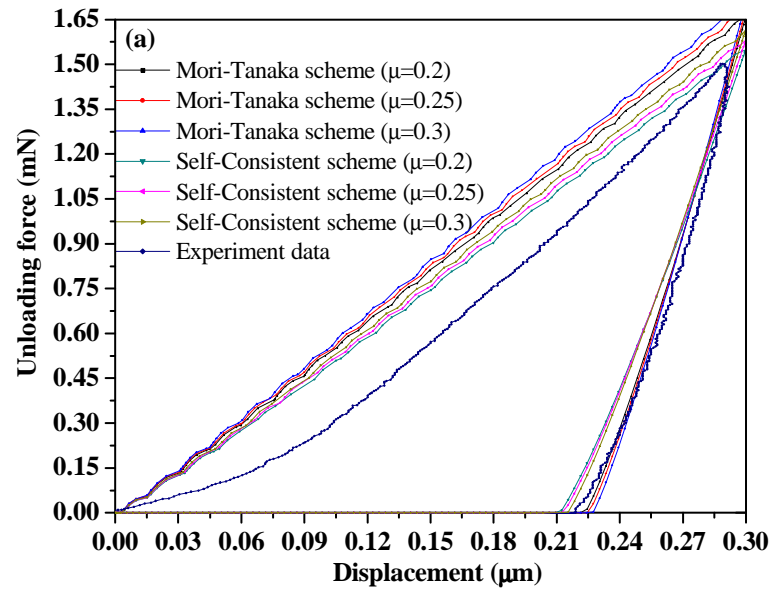

a) Comparison of experiment and MD simulation

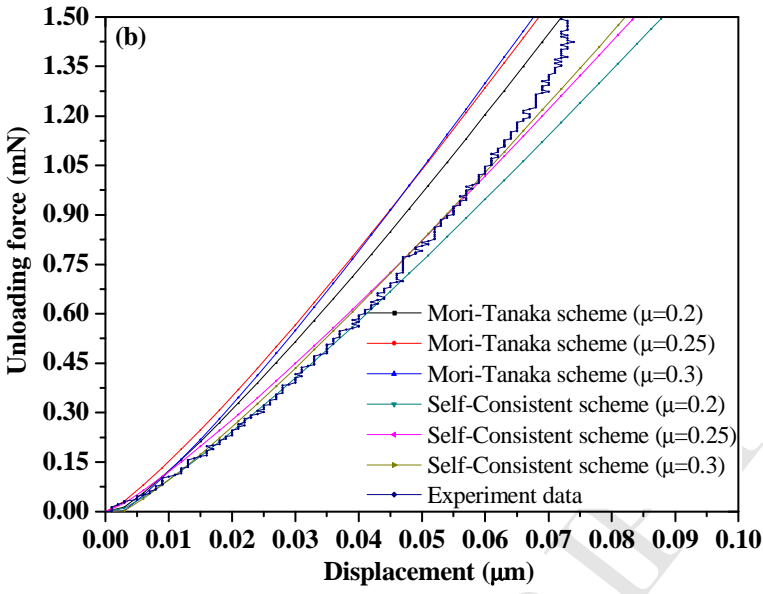

b) Unloading curves under various Poisson's ratio

Fig.18 Comparison of experimental and simulated unloading P-h curves of HD C-S-H phase 
Table 1 Elastic constants, shear modulus, bulk modulus and Young's modulus

\begin{tabular}{|c|c|c|c|c|c|c|c|c|c|c|c|}
\hline Method & $\mathrm{C}_{11}$ & $\mathrm{C}_{12}$ & $\mathrm{C}_{13}$ & $\mathrm{C}_{33}$ & $\mathrm{C}_{44}$ & $\mathrm{C}_{66}$ & $\mathrm{Bv}$ & $\mathrm{Br}$ & Gv & $\mathrm{Gr}$ & $\mathrm{E}$ \\
\hline DFT (Laugesen,2005) & 99.390 & 30.780 & 7.360 & 36.29 & 07.880 & 34.310 & 36.230 & 26.632 & 22.651 & 13.920 & 45.9460 .256 \\
\hline Brillouin (Speziale,2008) & 102.000 & 32.000 & 8.400 & 33.60 & 012.000 & 35.000 & 37.244 & 26.022 & 24.387 & 18.179 & 52.1520 .225 \\
\hline DFT method (present) & 108.021 & 30.998 & 39.951 & 36.69 & 314.092 & 38.512 & 39.393 & 28.406 & 26.795 & 20.656 & 57.7120 .216 \\
\hline Relative error (\%) & 5.903 & -3.131 & 18.464 & 9.205 & 17.433 & 10.034 & 5.77 & 9.161 & 9.874 & 13.626 & $10.661-$ \\
\hline
\end{tabular}


Table 2 Experimental parameters and corresponding characteristics of $\mathrm{CH}$ and $\mathrm{C}-\mathrm{S}-\mathrm{H}$ phases

\begin{tabular}{llll}
\hline Experimental parameters & LD C-S-H & HD C-S-H & CH \\
\hline Maximum depth $\mathrm{h}_{\max }(\mathrm{nm})$ & $441.79 \mathrm{~nm}$ & $278.08 \mathrm{~nm}$ & $212.98 \mathrm{~nm}$ \\
The projected contact area $\mathrm{A}_{\mathrm{p}}$ & $4577259.84 \mathrm{~nm}^{2}$ & $1761371.10 \mathrm{~nm}^{2}$ & $977898.05 \mathrm{~nm}^{2}$ \\
The unloading stiffness $\mathrm{S}$ & $0.0532 \mathrm{mN} / \mathrm{nm}$ & $0.0559 \mathrm{mN} / \mathrm{nm}$ & $0.0458 \mathrm{mN} / \mathrm{nm}$ \\
The fitting parameter $\mathrm{m}$ & 4.76 & 6.01 & 4.12 \\
Indent number) & 30 & 22 & 56 \\
\hline
\end{tabular}


Table 3 Mechanical properties parameters of $\mathrm{CH}$ and C-S-H phases used in simulation

a) Simulation parameters of the representative experimental $\mathrm{CH}$ and C-S-H phases

\begin{tabular}{llll}
\hline Phases/parameters & LD C-S-H & HD C-S-H & CH \\
\hline E (GPa) & 17.35 & 32.70 & 39.88 \\
\hline Friction coefficient f & 0.6 & 0.6 & 0.6 \\
Poisson's ratio v & $0.2-0.3$ & $0.2-0.3$ & $0.2-0.3$ \\
\hline
\end{tabular}

b) Simulation parameters of the CH, LD C-S-H and HD C-S-H structures

\begin{tabular}{|c|c|c|c|c|c|}
\hline \multirow{2}{*}{ Phases/parameters } & LD C-S-H & & HD C-S-H & $\mathrm{CH}$ & \\
\hline & S-C scheme & M-T scheme & S-C scheme M-T scheme & AFEM[58] & $\mathrm{DFT}+\mathrm{RVH}$ \\
\hline Elastic modulus E (GPa) & 18.22 & 29.78 & 31.63 & 43.13 & 45.46 \\
\hline Poisson's ratio $v$ & 0.25 & 0.25 & 0.25 & 0.25 & 0.20 \\
\hline Friction coefficient $\mathrm{f}$ & 0.6 & 0.6 & 0.6 & 0.6 & 0.6 \\
\hline
\end{tabular}

